\title{
Florística e fitossociologia de um trecho de um hectare de floresta de terra firme, em Caracaraí, Roraima, Brasil ${ }^{1}$ \\ Floristic composition and structure in one hectare of terra firme forest, Caracaraí, state of Roraima, Brazil
}

\author{
Juan Gabriel Soler Alarcón \\ Ariane Luna Peixotoll
}

Resumo: São apresentados dados florísticos e fitossociológicos de 1 ha de floresta de terra firme localizada na região do baixo rio Branco (0101'43"S, 6205'21"W), Roraima, Brasil. A amostragem incluiu os indivíduos arbóreos, lianas e hemiepífitas com DAP $\geq 10 \mathrm{~cm}$. A altura média da floresta é de 16,63 m, com árvores emergentes que alcançaram alturas de 58, 48 e 47 m. Foram encontrados 544 indivíduos pertencentes a 194 espécies, das quais cinco estavam representadas por lianas e duas por hemiepífitas. As famílias de maior riqueza específica foram Leguminoseae, Cecropiaceae, Burseraceae, Chrysobalanaceae e Moraceae. Os gêneros de maior riqueza específica foram Pourouma, Inga, Licania, Protium e Pouteria. As espécies com densidades maiores foram Clathrotropis macrocarpa, Bocageopsis multiflora, Eschweilera coriacea, Euterpe precatoria, Inga alba, Pourouma cf. tomentosa subsp. apiculata. Dezessete famílias e 76 gêneros estiveram representados por apenas uma espécie; 40 gêneros e 104 espécies representados por apenas um indivíduo. As famílias com maiores valor de importância (VI) foram Leguminosae, Cecropiaceae, Lecythidaceae, Annonaceae e Arecaceae. Os maiores VI para espécies foram de Clathrotropis macrocarpa, Goupia glabra, Bocageopsis multiflora, Eschweilera coriacea, Euterpe precatoria. A área basal total foi 26,35 m². O índice de Shannon ( $\left.H^{\prime}\right)$ 4,66 e a equabilidade (J) 0,88. A região de interfúlvio entre o rio Branco e o rio Negro, em relação à flora, era dita como insuficientemente conhecida, mas de provável importância. Os dados e informações aqui apresentados e discutidos apontam a importância florística da floresta de terra firme da área.

Palavras-chave: Inventário florístico. Estrutura fitosociológica. Floresta de terra firme. Amazônia brasileira.

Abstract: A quantitative floristic and phytosociological inventory in a 1 ha of terra firme forest were conducted in the region of the lower rio Branco $\left(01^{\circ} 01^{\prime} 43^{\prime \prime} S, 62^{\circ} 05^{\prime} 21^{\prime \prime} \mathrm{W}\right)$, Roraima, Brazil. This study included trees, lianas and hemiepiphytes with $\mathrm{DBH} \geq 10 \mathrm{~cm}$. The average height of the forest was 16,63 m, with canopy trees of 58, 48 e $47 \mathrm{~m}$. The plot had 544 individuals, 194 species, of which five were represented by lianas and two by hemiepiphytes. The richest families were Leguminoseae, Cecropiaceae, Burseraceae, Chrysobalanaceae and Moraceae. The richest genera were Pourouma, Inga, Licania, Protium e Pouteria. The species with highest densities were Clathrotropis macrocarpa, Bocageopsis multiflora, Eschweilera coriacea, Euterpe precatoria, Inga alba, Pourouma cf. tomentosa subsp. apiculata. A total of 17 families and 76 genera were represented by only one individual; 40 genera and 104 species by only one individual. The families with the highest important value (IV) were Leguminosae, Cecropiaceae, Lecythidaceae, Annonaceae e Arecaceae. The highest IV for the species was found in Clathrotropis macrocarpa, Goupia glabra, Bocageopsis multiflora, Eschweilera coriacea, Euterpe precatoria. The basal area was $26,35 \mathrm{~m}^{2}$. The Shannon index $\left(\mathrm{H}^{\prime}\right)$ found was 4,66 and the equitability $(\mathrm{J}) 0,88$. This region, which is localized between the rivers Branco and Negro, is said to have been poorly studied with respect of the flora but of probable importance. The data and information presented shows the floristic importance of the forest of terra firme in this area and looks forward to provide tools that will allow to compare this study with similar ones carried out in the Amazon.

Keywords: Floristic composition. Structure phytosociology. Terra firme forest. Brazilian Amazon.

\footnotetext{
1 Parte da dissertação de mestrado do primeiro autor, desenvolvida na Escola Nacional de Botânica Tropical do Instituto de Pesquisas Jardim Botânico do Rio de Janeiro, com o apoio financeiro e logístico da Fundação Caiuá de Gestão Ambiental.

I Instituto de Pesquisas Jardim Botânico do Rio de Janeiro. Rio de Janeiro, Rio de Janeiro, Brasil (juan@jbrj.gov.br).

"Instituto de Pesquisas Jardim Botânico do Rio de Janeiro. Rio de Janeiro, Rio de Janeiro, Brasil (ariane@jbrj.gov.br).
}

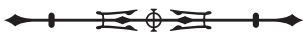




\section{INTRODUÇÃO}

A região amazônica ocupa uma área aproximada de 6 milhões de $\mathrm{km}^{2}$ na América do Sul, dos quais cerca de 60\% encontram-se em território brasileiro (Pires, 1980). O relevo é um dos fatores principais para determinar o tipo de vegetação, a qual está dividida em dois grupos principais: a vegetação de terra firme e a vegetação que sofre inundação (Pires; Prance, 1985).

Outra forma prática para expressar as diferenças entre tipos de vegetação é correlacionar as diferenças entre índices de biomassa: tipos de vegetação similares contém aproximadamente a mesma biomassa (área basal por hectare) (Pires; Prance, 1985). Com estes dois fatores, Pires e Prance (1985) classificam os principais tipos de vegetação da Amazônia. $\bigcirc$ presente estudo foi desenvolvido em floresta densa de terra firme, segundo esta classificação, e muitas vezes chamada na literatura simplesmente de floresta de terra firme (Milliken, 1998; Campbell et al., 1986; Ferreira; Prance, 1999, entre outros).

Embora a literatura hoje disponível sobre inventários florísticos e fitossociológicos em florestas de terra firme, várzea e igapó seja considerável, muitas vezes, é difícil comparar os resultados entre os diferentes inventários devido à diferença entre os métodos empregados, os critérios de inclusão de indivíduos e a grande diversidade local.

Campbell et al. (1986) tecem comentários sobre a dificuldade de fazer comparações entre diferentes inventários realizados na Amazônia porque muitos deles utilizam distintos critérios de inclusão. Apresentam uma tabela contendo 20 inventários realizados, incluindo o deles, que amostraram entre 0,5 e 3,8 ha com formato de área variado e critério de inclusão entre 8 e $15 \mathrm{~cm}$ de diâmetro a 1,3 m do solo (DAP).

Oliveira e Nelson (2001) fazem uma análise da composição florística em nível genérico entre 12 localidades da Amazônia brasileira, uma na Bolívia e uma na costa atlântica brasileira, com base em inventários publicados. Não analisaram os dados em nível específico por reconhecerem a existência de problemas de identificação botânica e nomenclatura das espécies.

Nelson e Oliveira (2001), escrevendo sobre o estado de conhecimento florístico da Amazônia, comentam sobre inventários quantitativos de árvores em florestas de terra firme e em florestas periodicamente inundadas, desde os primeiros realizados na região, em 1934, até os mais recentes. Apresentam uma tabela síntese de 37 destes inventários. Também comentam sobre as dificuldades nas comparações entre os diferentes estudos devido à variedade de metodologias, principalmente quanto à forma e tamanho da área amostral e diâmetro de inclusão. Ressaltam as dificuldades de se obter boas amostras de material testemunho e a complexidade de identificações destas amostras, o que dificulta ainda mais as comparações florísticas e estruturais ao nível de espécies.

Embora já seja significativo o conhecimento sobre a florística e a estrutura da floresta amazônica, quando se considera o tamanho e a diversidade biológica da região, a informação ainda é insuficiente para uma interpretação satisfatória da fitogeografia e da fitossociologia da região. $\mathrm{Na}$ revisão de literatura sobre inventários apresentada por Nelson e Oliveira, não há nenhuma citação para trabalhos realizados em Roraima. Entretanto, a região de interfúlvio rio Branco - rio Negro, onde o presente trabalho foi realizado, é apontada como área de alta importância biológica, prioritária para biodiversidade, com ausência de unidades de conservação e reconhecida como de alta importância biológica para aves, mamíferos, répteis e anfíbios. Suas florestas também são ditas como prioritárias para inventários e reconhecidas como área insuficientemente conhecida, mas de provável importância (Capobianco, 2001).

O presente estudo objetivou a busca de conhecimento sobre a estrutura e a composição florística de 1 ha da floresta de terra firme, considerando-se apenas árvores, lianas e hemiepífitas arbóreas com DAP $\geq 10 \mathrm{~cm}$. A pesquisa integra um estudo etnobotânico que visou a identificar a utilização das espécies desse mesmo trecho 
de floresta pela comunidade ribeirinha da vila de Caicubi; e responder duas questões principais: quais as espécies que ocorrem no trecho estudado e como estão representadas suas populações (dentro dos parâmetros de inclusão estabelecidos). Os dados e informações aqui apresentados e discutidos visaram a contribuir, também, para uma futura interpretação mais acurada do vasto espaço florestado da Amazônia, fornecendo ferramentas para a conservação.

\section{MATERIAIS E MÉTODOS}

O estudo foi realizado em 1 ha de floresta de terra firme, localizado próximo à vila Caicubi (com coordenada central de $01^{\circ} 01^{\prime} 43^{\prime \prime} S$ e $62^{\circ} 05^{\prime} 21^{\prime \prime} \mathrm{W}$, altitude de $50 \mathrm{msnm}$ ). Esta vila, habitada por 400 pessoas em 72 famílias (Orange Ferreira, comunicação pessoal), localiza-se na margem do igarapé Caicubi, afluente do rio Jufari, na região do baixo rio Branco (interflúvio rio Branco - rio Negro), município de Caracaraí, Roraima (Figura 1). As cidades mais próximas à vila de Caicubi são Barcelos e Manaus, localizadas no rio Negro, e Caracaraí, em Roraima, no rio Branco. Segundo a classificação de Veloso et al. (1991), a área de estudo é coberta por floresta ombrófila densa das terras baixas e, segundo a classificação de Pires e Prance (1985), floresta densa de terra firme.

O clima da região é tipicamente quente e úmido (Afi de Köepen). Vila Nova et al. (1976) apresentam dados climáticos de Barcelos (0`59'S, 6255'W), onde se localiza a estação meteorológica mais próxima a Caicubi, e apontam, em uma série de 30 anos (1931 a 1960), temperatura média anual de $26^{\circ} \mathrm{C}$; pluviosidade média anual de 1999 mm, sendo os meses mais chuvosos abril, maio e junho; umidade relativa de $86 \%$. O trecho estudado pertence à Formação Solimões; geomorfologicamente está classificado como interflúvio tabular de relevo de topo aplainado e solo classificado como Latossolo Amarelo Álico (RADAMBRASIL, 1978).

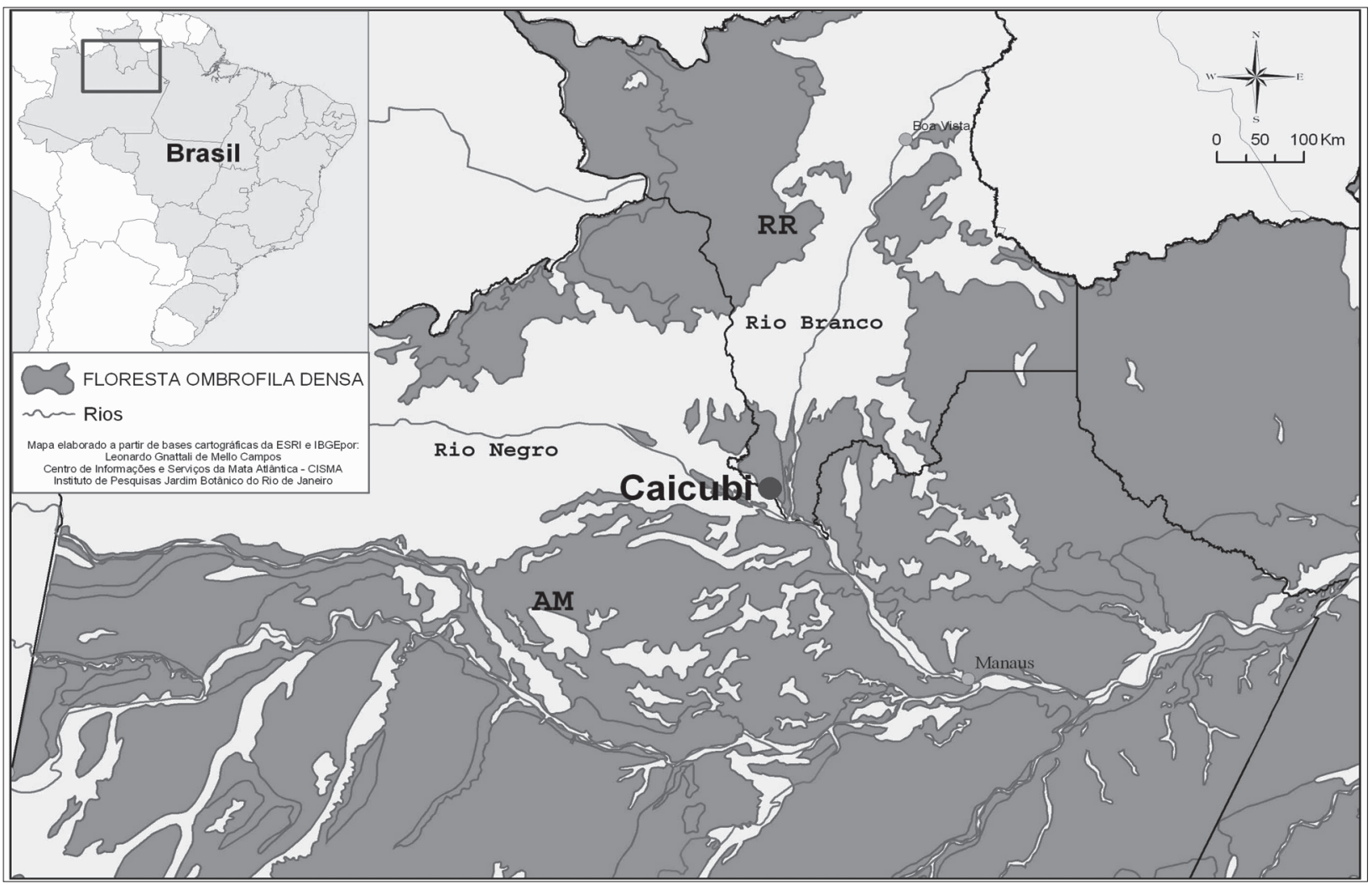

Figura 1. Mapa de localização do trecho de floresta de terra firme próximo à vila de Caicubi, Caracaraí, Roraima, Brasil.

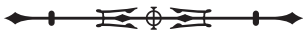


A escolha do trecho a ser estudado foi feita numa área que, de acordo como a população local, teve pouca intervenção, sendo apenas extraídos produtos não madeiráveis, principalmente açaí (Euterpe precatoria), bacaba (Oenocarpus bacaba), cipó-titica (Heteropsis cf. flexuosa), arumã (Ishnosiphon sp.), castanha (Bertholletia excelsa) e ubim (Geonoma spp.).

método escolhido para o estudo florístico e fitossociológico foi o de parcelas, de modo geral, empregado em estudos similares na Amazônia (Campbell et al., 1986; Milliken, 1998; Ferreira; Prance, 1999, entre outros). $\mathrm{Na}$ área previamente escolhida, delimitou-se 1 ha em forma de retângulo (200 m x 50 m) em direção Norte-Sul subdividido em parcelas de $10 \mathrm{~m} \times 10 \mathrm{~m}$. Optou-se por um retângulo, pois ao tentar-se delimitar um quadrado de $100 \mathrm{~m} \times 100 \mathrm{~m}$, foram encontrados castanhais nos quais a população local coleta frutos e para tal limpam parcialmente um trecho correspondente ao diâmetro das copas das castanheiras. A diferença de forma da parcela entre quadrado e retângulo, das dimensões empregadas, parece não influenciar significativamente em análises relativas à riqueza de espécies; retângulos mais estreitos (10 m x $1000 \mathrm{~m}$ ), entretanto, podem capturar maior riqueza (Laurance et al., 1998).

Dentro das parcelas, foram numerados, seqüencialmente, com pequenas placas de material plástico, todos os indivíduos arbóreos, lianas e hemiepífitas com DAP $\geq$ $10 \mathrm{~cm}$. Quando as árvores apresentavam sapopemas, o DAP era medido acima destas. Para todos os indivíduos, foram anotados, em planilhas, dados de altura total, altura do fuste, DAP e características morfológicas, como cor do ritidoma, exsudatos (látex, seiva, resina, goma), odor ou outros caracteres que pudessem auxiliar na identificação, bem como o nome popular. Entre novembro de 2003 e fevereiro de 2004, foram coletadas amostras das morfoespécies para identificação e depósito em herbários. A coleta foi realizada com tesoura de alta poda e, para os indivíduos com copas acima de 14 m, foi necessário escalar as árvores utilizando peconha, técnica amplamente utilizada pelos habitantes da região, para a coleta de alguns produtos das palmeiras de açaí (Euterpe precatoria), bacaba (Oenocarpus bacaba) e patauá (Oenocarpus bataua), entre outras. As amostras botânicas foram prensadas em jornal e preservadas em álcool durante todo o período de permanência no campo; após, foram secas em estufa nos laboratórios do Instituto Nacional de Pesquisas da Amazônia (INPA). A coleção completa das amostras foi depositada no herbário do Jardim Botânico do Rio de Janeiro (RB) e duplicatas de exemplares férteis foram depositadas no herbário do INPA.

A identificação taxonômica foi realizada inicialmente no campo, utilizando-se os livros de Gentry (1993) e Ribeiro et al. (1999), muito empregados em identificação de espécies vegetais. Após esta etapa, as identificações foram confirmadas com literatura especializada e comparando-se as amostras com os exemplares depositados nos herbários do INPA e RB. Especialistas em taxonomia confirmaram ou retificaram as identificações das famílias Lauraceae, Burseraceae, Moraceae e Leguminoseae. Não foi possível identificar três espécimes que foram tratados como um grupo separado, denominado de 'indeterminadas'. Estes espécimes permaneceram desfolhados durante toda a permanência em campo, o que impossibilitou também a coleta para constituir exemplares testemunhos. Três morfoespécies idênticas a táxons ainda não descritos formalmente, porém citados em Ribeiro et al. (1999), como Ocotea sp. E, Aniba aff. Williamsii e Qualea sp.1, são aqui citadas dessa forma.

Seguiu-se o sistema de classificação de Cronquist (1981), excetuando Leguminosae, que foi considerada como família única, como indicado por Polhill e Raven (1981). Optou-se por este procedimento para possibilitar uma melhor comparação entre o trecho estudado e outros estudos realizados na região amazônica. A grafia dos nomes das espécies foi conferida em revisões taxonômicas ou no Index Kewensis, versão on line. Os nomes dos autores das espécies encontram-se abreviados segundo Brummit e Powel (1992). Os nomes populares foram indicados por 
11 colaboradores da vila de Caicubi que auxiliaram nos trabalhos de campo.

O programa Fitopac 1 (Shepherd, 1995) foi utilizado para analisar os parâmetros fitossociológicos. No caso das espécies e das famílias, foram calculados os valores absolutos e relativos de densidade, freqüência e dominância e os valores de importância (VI) (Müller-Dombois; Ellenberg, 1974), assim como o índice de diversidade de Shannon $\left(H^{\prime}\right)$ e a equabilidade $(J)$ (Magurran, 1988).

\section{RESULTADOS E DISCUSSÃO}

No trecho de 1 ha de floresta de terra firme, foram encontrados 544 indivíduos, distribuídos em 43 famílias, 106 gêneros e 192 espécies. Em realção ao hábito, 185 eram de espécies arbóreas (em 100 gêneros), seguido pelas lianas com cinco espécies (em quatro gêneros e uma indeterminada) e hemiepífitas com duas espécies (em dois gêneros). Na Tabela 1, são apresentadas as espécies, em ordem alfabética de famílias, seus nomes populares e o número de coleta do exemplar testemunho.

A família com maior riqueza específica foi Leguminosae, com 32 espécies, 17 delas pertencentes à subfamília Mimosoideae, oito à subfamília Papilionoideae e sete à subfamília Caesalpinoideae. As outras famílias com maior riqueza de espécies foram Cecropiaceae (13 espécies), Burseraceae (11), Chrysobalanaceae (11) e Moraceae (10). Foram encontradas 17 famílias representadas por apenas uma espécie.

A família Leguminosae também se caracterizou por apresentar o maior número de indivíduos (102), pertencendo 46 deles à subfamília Papilionoideae, 43 à Mimosoideae e 13 à Caesalpinioideae. As outras famílias com maior número de indivíduos foram Cecropiaceae (51), Lecythidaceae (46), Annonaceae (42) e Arecaceae (32). Foram encontradas dez famílias representadas por apenas um indivíduo (Tabela 2).

Os gêneros que apresentaram maior riqueza de espécies foram Pourouma (11), Inga (dez), Licania (nove), Protium (sete) e Pouteria (seis). Estiveram representados por apenas uma espécie 76 gêneros. Em relação ao número de indivíduos por gênero, Pourouma foi o mais abundante, com 45 indivíduos, seguido por Clathrotropis (39), Eschweilera (35), Bocageopsis (30) e Inga (29). Gêneros representados por apenas um indivíduo totalizaram 40.

gênero Pourouma destacou-se como mais abundante porque somou os indivíduos de dois táxons bem representados na área, $P$. cf. tomentosa subsp. apiculata (15 indivíduos) e P. minor (13). As outras nove espécies estiveram assim representadas: duas espécies com quatro indivíduos, duas espécies com dois indivíduos e cinco espécies com apenas um indivíduo.

As espécies com maior número de indivíduos foram Clathrotropis macrocarpa (39), Bocageopsis multiflora (30), Eschweilera coriacea (21), Euterpe precatoria (20), Inga alba (15) e Pourouma cf. tomentosa subsp. apiculata (15). Estas seis espécies representaram 3\% do total de espécies, porém, 25,7\% dos indivíduos amostrados (Figura 2).

Do total de 192 espécies, apenas 11 estiveram representadas por dez ou mais indivíduos, as quais, juntas, representaram 38,2\% dos indivíduos. Também é interessante ressaltar que as 25 espécies com densidades maiores representam $51,6 \%$ do total dos indivíduos. Isto corrobora com Pires e Prance (1985), quando afirmam que não existe uma espécie dominante nas florestas úmidas tropicais; entretanto, sempre vai existir um grupo de espécies dominantes, entre cinco a dez ou, às vezes, até 30, que quando somados seus indivíduos ultrapassam $50 \%$ do total.

O surgimento progressivo de novas espécies amostradas encontra-se representado na curva espécies/área (curva do coletor) da Figura 3. O número de espécies amostradas em cada subparcela de $10 \mathrm{~m} \times 10 \mathrm{~m}$ variou de 1 a 10 . Observase que, embora tenha havido dois pontos de aparente estabilidade entre 0,52 a 0,56 ha e entre 0,85 a 0,88 ha, não há, no final da amostragem, uma estabilidade, demonstrando que a área é insuficiente para uma boa representação da riqueza da floresta de terra firme. Tal informação corrobora com pesquisas realizadas por Campbell et al. (1986) e Milliken 
Tabela 1. Espécies arbóreas, lianas e hemiepífitas com DAP $\geq 10 \mathrm{~cm}$ amostradas em 1 ha de floresta de terra firme na vila de Caicubi, Caracaraí, Roraima, Brasil; seus nomes comuns utilizados localmente; e número de coleta de Juan G. Soler A. (* Hemiepífita; **Lianas;

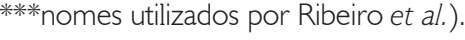

\section{ANACARDIACEAE}

Tapirira guianensis Aubl.

\section{ANNONACEAE}

Bocageopsis multiflora (Mart.) R. E. Fr.

Envira-surucucu, envira-ferro, envira-preta

Fusaea longifolia Safford.

Envira-ferro

Guatteria citriodora Ducke

Envira-pimenta, envira

Xylopia aff. polyantha R. E. Fr.

Envira-preta, envirera

Xylopia amazonica R. E. Fr.

Envira-vasourinha, envira-surucucu-vermelha

\section{APOCYNACEAE}

Ambelania acida Aubl.

Pepino-do- mato

Couma guianensis Aubl.

Sorva, sorvão

Odontadenia cognata (Stadelm.) Woodson ***

Cipó-cururu

Rhigospira quadrangularis Miers.

Balatarana

AQUIFOLIACEAE

Ilex divaricata Mart ex Reiss.

ARALIACEAE

Schefflera morototoni (Aubl.) Maguire, Steyerm. \& Frodin

Morototo, murucututu

8

ARECACEAE

Astrocaryum aculeatum Wallace

Tucumã

$\mathrm{S} / \mathrm{C}$

Attalea maripa Mart.

Inajá

$\mathrm{S} / \mathrm{C}$

Euterpe precatoria Mart.

Açaí

$\mathrm{S} / \mathrm{C}$

Oenocarpus bacaba Mart.

Bacaba, bacabeira

$\mathrm{S} / \mathrm{C}$

BIGNONIACEAE

Jacaranda copaia D. Don

Para-pará

S/C

BOMBACACEAE

Quararibea ochrocalyx Visch.

Envira-branca

25

Rhodognaphalopsis cf. duckei A. Robyns

BORAGINACEAE

Cordia bicolor A. DC. ex DC.

Cordia exaltata Lam.

Envira-pimenta, envira-tai

Cordia nodosa Lam.

Ovo-de-mucura, saco-de-mucura

Cordia panicularis Rudge

Envira-preta, embira

76

Cordia sp. 
Tabela 1. Espécies arbóreas, lianas e hemiepífitas com DAP $\geq 10 \mathrm{~cm}$ amostradas em 1 ha de floresta de terra firme na vila de Caicubi, Caracaraí, Roraima, Brasil; seus nomes comuns utilizados localmente; e número de coleta de Juan G. Soler A. (* Hemiepífita; ***ianas; ****nomes utilizados por Ribeiro et al.).

\section{BURSERACEAE}

Crepidospermum cf. rhoifolium (Benth.) Triana \& Planchon

Dacryodes cf. hopkinsii Daly

Breeira, tinturana

Dacryodes sclerophylla Cuatrec.

Breu-cicantaá

Protium amazonicum (Cuatrec.) Daly

Breera, breu-cajarana

Protium grandifolium Engl.

Breu-cicantaá, cicantaá-de-inambú

Protium hebetatum Daly

Breu-cicantaá, breu

Protium opacum Swart subsp. Opacum

Moela-de-inambu, breeira-da-folha-graúda

Protium subserratum Engl.

Moela-de-inambu, tinturana

Protium trifoliolatum Engl.

Breu

Trattinnickia boliviana (Swart.) Daly

Breu-cicantaá

Trattinnickia glaziovii Swart.

Breera-breu xicantá, cajarana

\section{CARYOCARACEAE}

Caryocar glabrum (Aubl.)

Pers. subsp. parviflorum (A. C. Sm.) Prance \& M.F. da Silva

Piquiarana

Caryocar glabrum (Aubl.) Pers. subsp. glabrum

Piquiarana

\section{CECROPIACEAE}

Cecropia distachya Huber

Imbaúba-branca, imbaúba-da-folha-graúda

Coussapoa sprucei Mildbr.*

Mata-pau

Pourouma cf. cuspidata Warb. \& Mildbr.

Imbaúba, imbaubarana

Pourouma cf. tomentosa subsp. apiculata (Benoist)

C. C. Berg \& Van

Imbaubão, cucuraí, imbaúba-da-terra-firme

Pourouma cucura Standl. \& Cuatrec.

Imbaúba-branca, imbaúba, cucura

Pourouma ferruginea Standl.

Imbaúba, cucurarana, cucura

Pourouma guianensis Aubl. subsp. guianensis

Imbaúba-bengüe, caimbe, cucura-do-mato

Pourouma melinonii Benoist subsp. melinonii

Imbaubão, cucura, imbaúba

Pourouma minor Benoist

Imbaúba-branca, imbaúba, imbaúba-de-folha-miúda

Pourouma ovata Trec.

Imbaúba-branca, cucurarana, cucura,

Pourouma tomentosa Miq. subsp. essequiboensis (Stand.)

C. C. Berg \& Heusden

Imbaúba-branca, cucura-do-mato

Pourouma tomentosa Miq. subsp. tomentosa

Imbaúba, cucurai, imbaúba-branca 
Tabela 1. Espécies arbóreas, lianas e hemiepífitas com DAP $\geq 10 \mathrm{~cm}$ amostradas em 1 ha de floresta de terra firme na vila de Caicubi, Caracaraí, Roraima, Brasil; seus nomes comuns utilizados localmente; e número de coleta de Juan G. Soler A. (* Hemiepífita; **Lianas;

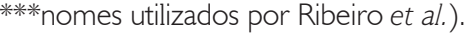

(continua)

FAMÍLIAS/ESPÉCIES

\section{CHRYSOBALANACEAE}

Couepia aff. obovata Ducke

Hirtella racemosa var. hexandra (Willdenow ex Roemer \& Schultes) Prance

Licania canescens Benoist

Licania caudata Prance

Licania cf. prismatocarpa Spruce ex Hook. F.

Licania heteromorpha Benth. subsp. heteromorpha

Licania hirsuta Prance

Licania micrantha Miq.

Licania octandra subsp. pallida (Hooker f.) Prance

Licania sothersiae Prance

Licania unguiculata Prance

CLUSIACEAE

Clusia grandiflora Splitg. *

Symphonia globulifera L.

Tovomita schomburgkii Planch. \& Triana

DILLINIACEAE

Pinzona coriacea Mart. \& Zucc. *

ELAEOCARPACEAE

Sloanea cf. synandra Spruce ex. Benth.

Sloanea pubescens Benth.

Sloanea rufa Planch. ex Benth.

Sloanea sp.1

\section{EUPHORBIACEAE}

Alchornea schomburgkii Klotzsch

Alchornea triplinervia Mull. Arg.

Croton lanjouwensis Jabl.

Dima

Urucurana

Urucurana

278

Canela-de-velho, canela-de-maçarico

Urucurana

Hieronyma mollis Muell. Arg.

Euphorbiaceae sp.1

\section{FLACOURTIACEAE}

Laetia procera Eichl.

Pau-judeu, matutexi, matute

Laetia sp.1 
Tabela 1. Espécies arbóreas, lianas e hemiepífitas com DAP $\geq 10 \mathrm{~cm}$ amostradas em 1 ha de floresta de terra firme na vila de Caicubi, Caracaraí, Roraima, Brasil; seus nomes comuns utilizados localmente; e número de coleta de Juan G. Soler A. (* Hemiepífita; ***ianas; ****nomes utilizados por Ribeiro et al.).

(continua)

FAMÍLIAS/ESPÉCIES

NOMES POPULARES

No Col.

GNETACEAE

Gnetum leyboldii Tul.***

Cipó-curucuda, cipó-tuiri

HUGONIACEAE

Hebepetalum humiriifolium (Planch.) Jackson

Suim

LAURACEAE

Aniba aff. williamsii O. C. Schmidt ****

Louro-rosa, abacaterana, louro-chumbo

Licaria guianensis Aubl.

Louro-alitú, louro-gavali

Mezilaurus subcordata (Ducke) Kosterm

Ocotea nigrescens A. Vicentini

Louro-preto, louro-santo, louro-chumbo, marirana

Ocotea rhodophylla A. Vicentini

Louro-rosa, louro-bosta, louro-alitu, marirana

Ocotea sp. E *****

Abacaterana, louro-bosta

Ocotea subterminalis $\mathrm{H}$. van der Werff

Louro-santo

Pleurothyrium vasquezii $\mathrm{H}$. van der Werff

Louro-chumbo, louro-abacaterana

LECYTHIDACEAE

Bertholletia excelsa Humb \& Bonpl.

Castanheira

Eschweilera bracteosa Miers

Matamata-preto, matamata

Eschweilera coriacea Mart. ex O. Berg

Ripeira, matamata, matamata-preto,

matamatá-folha-graúda

Eschweilera grandifolia Mart ex DC.

Matamata-branco, sapucaia-castanha, catanharana

Eschweilera pedicellata (Richard) S. A. Mori

Matamata-preto, matamata-folha-miúda, canhizera

Gustavia augusta Amoen. Acad.

Envira-de-cutia, periquito-castanha, ripeira

Lecythis poiteaui O. Berg.

Envira-de-cutia, envira-de-periquito, cuyombo, ripeira

Lecythis retusa Spruce ex O. Berg

Envira-de-cutia, matamata,

castanha-sapucaia, cajurana

Lecythis zabucaja Aubl.

Castanha-sapucaia, piquiteira, ripeira

LEGUMINOSAE

\section{CAESALPINIOIDEAE}

Bauhinia guianensis Aubl. ***

Escada-de-jabuti

Dicorynia paraensis Benth.

Coração-de-negro, tintarana

Sclerolobium aff. setiferum Ducke

Tachi-preto, tachi

Sclerolobium chrysophyllum Poepp. \& Endl.

Tachi-vermelho, tachi

Sclerolobium setiferum Ducke

Tachi-preto, tachi

Tachigali myrmecophila Ducke

Tachi, tachi-preto, tachi-vermelho 
Tabela 1. Espécies arbóreas, lianas e hemiepífitas com DAP $\geq 10 \mathrm{~cm}$ amostradas em 1 ha de floresta de terra firme na vila de Caicubi, Caracaraí, Roraima, Brasil; seus nomes comuns utilizados localmente; e número de coleta de Juan G. Soler A. (* Hemiepífita; ***ianas; ****nomes utilizados por Ribeiro et al.).

(continua)

FAMÍLIAS/ESPÉCIES

\section{MIMOSOIDEAE}

Cedrelinga cataeniformis (Ducke) Ducke

Dinizia excelsa Ducke

Enterolobium schomburgkii Benth.

Inga aff. bicoloriflora Ducke

Inga aff. Capitata Desv.

Inga alba (Swartz) Willd.

Inga cf. laurina Willd.

Inga cf. paraensis Ducke

Inga grandiflora Ducke

Inga paraensis Ducke

Inga rhynchocalyx Sandwith

Inga thibaudiana DC.

Inga umbratica Poepp. \& Endl.

Parkia sp.

Parkia nitida Miq.

Pseudopiptadenia psilostachya (DC.) G. Lewis \& M. P. M. de Lima Angelim-babão, cavivi-da-terra-firme, sucupira-branca

Stryphnodendrom paniculatum Poepp. \& Endl.

Zygia racemosa (Ducke) Barneby \& J. W. Grimes PAPILIONOIDEAE

Andira micrantha Ducke

Clathrotropis macrocarpa Ducke

Papilionoideae sp. 1

Ormosia aff. nobilis Tul. var. nobilis

Ormosia grossa Rudd.

Pterocarpus officinalis Jacq.

Swartzia cf. dolichopoda R. S. Cowan

Swartzia corrugata Benth.

MELASTOMATACEAE

Miconia traillii Cogn.

Goiaba-de-anta, canelha-de-velha, buchucho

№ Col.

Cedrarana, cedrão-vermelho 300

Angelim, paracaxii, angelim-pedra, cavivi-da-terra-firme 246

Angelim, sucupira, cavivi-da-terra-firme 267

Ingá, ingarana, ingá-xixica 236

Ingá-de-macaco, ingá-xixica, ingá-preto 153

Ingá-xixica, ingarana 73

Ingá-xixica, ingarana 238

Ingá-de-macaco 245

Ingarana 206

Ingá-de macaco, ingá-xixica, ingá-preto, ingaí, cumanda 48

Ingá-xixica, ingarana $\quad 37$

Ingarana, ingá-xixica, ingá-preto 189

Ingarana, ingá-de-macaco, ingá-xixica, 31

Piradabi-do-mato 90

Piradabi-do-mato, angelirana, $\quad 80$

piradabi-da-terra-firme, fava

Pau-santo, rabo-de-tatu, angelim, cavivi-da-terra-firme 28

Sucupira-amarela, cavari-babão $\quad 237$

Amarelinho, cavari, baudera, paratari 92

Tento, tento-vermelho 112

Tento 277

Sucupira-preta, jutaí-pororoca, cavivirana 222

Coração-de-nego 157

Tento, tenturana

MELIACEAE

Guarea guidonia (L.) Sleumer

Guarea silvatica C. DC. 
Tabela 1. Espécies arbóreas, lianas e hemiepífitas com DAP $\geq 10 \mathrm{~cm}$ amostradas em 1 ha de floresta de terra firme na vila de Caicubi, Caracaraí, Roraima, Brasil; seus nomes comuns utilizados localmente; e número de coleta de Juan G. Soler A. (* Hemiepífita; ***ianas; ****nomes utilizados por Ribeiro et al.).

\section{MORACEAE}

Clarisia racemosa Ruiz \& Pav.

Helianthostylis sprucei Baill.

Anani-branco

Helicostylis tomentosa (Poepp. \& End.) Macbride

Muiratinga, pé-de-jabuti, fruta-de-jabuticaba

Maquira sclerophylla (Ducke) C. C. Berg.

Muiratinga, abiurana-branca

Moraceae sp.1

Paratari-branco, saboarana-da-terra-firme, mirapiringa

Naucleopsis glabra Spruce ex Pittier

Muiratinga, pé-de-jabuti

Perebea guianensis Aubl.

Perebea mollis (Planch. \& Endl.) Huber subsp. mollis

Muiratinga, pé-de-jabuti, jaboticaba

Pseudolmedia laevis (Ruiz \& Pav.) Macbride

Muiratinga, pé-de-jabuti, tinteira, jaboticaba

Sorocea guilleminiana Gaudich.

Muiratinga, taquari-da-terra-firme, muiratinga, manichi

MYRISTICACEAE

Iryanthera juruensis Warb.

Piranha caã, matacalado, língua-de-tucano

Iryanthera coriacea Ducke

Copeira, punã, lacre, taquari

Iryanthera grandis Ducke

Copeira, punã, jïgua

Punarana, virola

Osteophloeum platyspermum Warb.

Marupa-vermelho, pau-pra-tudo,

miracêe, uicui, copeira

Virola calophylla Warb.

Envirola, ucuuba, puna-da-folha graúda, ucuuba, lacre

Virola enlongata (Benth.) Warb.

Ucuuba-vermelha, puna, puna-branca

Virola theiodora Warb.

Virola-branca, ucuuba-vermelha, copeira,

punã, virola, ucuuba

Virola venosa Warb.

Punarana, virola, taquari, copeiro-branco

MYRSINACEAE

Cybianthus aff. detergens Mart.

Tintarana-da-terra-firme

\section{MYRTACEAE}

Calycolpus sp.

Araçarana, araçá, pau-mulato

Eugenia aff. florida DC.

Daicú, tintarana, caçari-da-terra-firme, araçá

Eugenia cf. cuspidifolia DC.

Pau vidro, guajabinha, caçari-da-terra-firme

Eugenia cf. omissa McVaugh

Pau-vidro, araçá, araçarana

Eugenia sp.1

Chumberi, tamandaré, araçá-do-mato

Myrcia aff. rufipila McVaugh

Pau-vidro, araçá, mustinha, ouvido-de-peixe

Myrcia sylvatica DC.

Araçarana, caçari-da-terra-firme, araçá, pau-mulato

OLACACEAE

Minquartia guianensis Aubl. 
Tabela 1. Espécies arbóreas, lianas e hemiepífitas com DAP $\geq 10 \mathrm{~cm}$ amostradas em 1 ha de floresta de terra firme na vila de Caicubi, Caracaraí, Roraima, Brasil; seus nomes comuns utilizados localmente; e número de coleta de Juan G. Soler A. (* Hemiepífita; **Lianas;

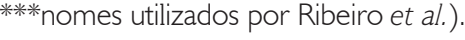

\section{QUIINACEAE}

Quiina florida Tul.

Touroulia guianensis Aubl.

ROSACEAE

Prunus myrtifolia Urb.

Carapitiu-da-terra-firme, daicurana, pau-cravo

RUBIACEAE

Borojoa claviflora (K. Schum.) Cuatrec.

Apuruí

Ferdinandusa rudgeoides Wedd.

Itaubarana

Ferdinandusa sp.1

Itaubarana-da-folha-miúda

SABIACEAE

Ophiocaryon aff. manausense (W. A. Rodrigues) Barneby

Tamaquarerana

\section{SAPINDACEAE}

Cupania scrobiculata Rich.

\section{SAPOTACEAE}

Chrysophyllum sanguinolentum (Pierre) Baehni

Abiurana

Micropholis guyanensis (A. DC.)

Pierre subsp. guyanensis

Cedrinho, cedro-branco, caramuri, balatarana

Pouteria caimito Radlk.

Abiurana-ferro, abiurana 145

Pouteria cuspidata (A. DC.) Baehni

Mortinha

Pouteria durlandii (Standl.) Baehni

Abiurana, abiurana-ferro $\quad 74$

Pouteria glomerata Radlk.

Abiurana, abiurana-ferro, araru 131

Pouteria guianensis Aubl.

Abiurana-ferro, abiurana $\quad 34$

Pouteria sp.1

Taquari, goiaba-de-jabuti

SIMAROUBACEAE

Simaba polyphylla (Cavalcante) W. W. Thomas

Cajurana

Simarouba amara Aubl.

Marupá, marupá-branco

STERCULIACEAE

Theobroma microcarpa Mart.

Theobroma obovatum Klotzch ex Bernoulli

Envira, biriba, biriba-do-mato, cupuí-bravo

Theobroma speciosa Willd. ex Spreng.

Cupuí-bravo

Theobroma subincanum Mart.

Cacau, cupu-do-mato

Theobroma sylvestris Aubl. ex Mart.

Cupuí

\section{STRELITZIACEAE}

Phenakospermum guyanense (L. C. Rich.) Endl. 
Tabela 1. Espécies arbóreas, lianas e hemiepífitas com DAP $\geq 10 \mathrm{~cm}$ amostradas em 1 ha de floresta de terra firme na vila de Caicubi, Caracaraí, Roraima, Brasil; seus nomes comuns utilizados localmente; e número de coleta de Juan G. Soler A. (* Hemiepífita; ***ianas; *****mes utilizados por Ribeiro et al).

(conclusão)

\begin{tabular}{lll} 
FAMÍLIAS/ESPÉCIES & NOMES POPULARES & No Col. \\
\hline TILIACEAE & Biriba-do-mato, biribarana, bolacheira, bolacharana & 83 \\
Apeiba echinata Gaertn. & & \\
VIOLACEAE & Abacaterana & 91 \\
Paypayrola sp. & & \\
VOCHYSIACEAE & Ripeira & 140 \\
Erisma bracteosum Ducke & Cafearana-branca, cafearana & 64 \\
Qualea paraensis Ducke & Cupiubarana & 243 \\
Qualea sp.1 * $^{*} *$ & Macucui-da-branca & 108 \\
Vochysia vismiaefolia Spruce ex Warm. & & \\
INDETERMINADAS & & S/C \\
Indet. sp.1 & & S/C \\
Indet. sp.2 $*$ ** & & S/C \\
Indet. sp.3 & & \\
\hline
\end{tabular}

(1998), que observaram também ser insuficiente os dados de 1 ha na floresta de terra firme da Amazônia para uma avaliação acurada da riqueza de espécies.

As espécies representadas por apenas um indivíduo somam 104, ou seja, 54,2\% do total (Figura 4). As cinco espécies de lianas e as duas espécies de hemiepífitas amostradas estiveram representadas por apenas um indivíduo. Considerando como espécies raras aquelas representadas por apenas um indivíduo em 1 ha, Martins (1991) compara alguns trabalhos realizados em florestas brasileiras e cita três inventários em áreas de 1 ha na Amazônia que utilizaram, como critério de inclusão, árvores com DAP $\geq 10 \mathrm{~cm}$ : Pires et al. (1953), em floresta de terra firme em Castanhal, Pará, encontraram 45 espécies raras (25,14\%); Black et al. (1950), em floresta de terra firme em Tefé, Amazonas, encontraram 42 de espécies raras (53,16\%); e Porto et al. (1976), em 'mata de baixio' em Manaus, Amazonas, encontraram 58 espécies raras (50,88\%).

O índice de Shannon ( $\left.H^{\prime}\right)$ encontrado foi 4,652 e a equitabilidade (J) 0,885 . Os altos valores para o índice de
Shannon e de equitabilidade podem ser atribuídos ao grande número de espécies raras (54,2\%). Considerando apenas as espécies arbóreas, os valores para H' e J foram 4,616 e 0,884 , respectivamente. $\bigcirc$ número de espécies raras encontrado em Caicubi, maior do que qualquer outro citado anteriormente, e os altos valores do índice de diversidade e da equitabilidade corroboram com o comentário exposto em Capobianco (2001), que o interflúvio entre os rios Branco e Negro é uma área de alta diversidade e estudos são necessários para inventariar a sua biota.

As cinco famílias de mais alto VI no trecho estudado foram Leguminosae $(59,77)$, Cecropiaceae $(24,91)$, Lecythidaceae $(24,60)$, Annonaceae $(19,79)$ e Arecaceae $(14,26)$ (Tabela 2).

$\mathrm{Na}$ Tabela 3 são apresentadas as espécies com seus respectivos parâmetros fitossociológicos, em ordem decrescente do VI. As cinco espécies com maior VI foram Clathrotropis macrocarpa, Goupia glabra, Bocageopsis multiflora, Eschweilera coriacea e Euterpe precatoria, representando, juntas, 21,87\% dos indivíduos amostrados

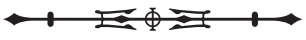


Tabela 2. Famílias listadas em ordem decrescente de valor de importância (VI), com número de indivíduos ( $N^{\circ}$ Ind.) e número de espécies (No Spp.) encontradas na vila de Caicubi, Caracaraí, Roraima, Brasil.

(continua)

\begin{tabular}{|c|c|c|c|}
\hline Família & $\mathrm{N}^{0}$ Ind & No Spp & VI \\
\hline Leguminosae & 102 & 32 & 59.77 \\
\hline Cecropiaceae & 51 & 13 & 24.91 \\
\hline Lecythidaceae & 46 & 9 & 24.60 \\
\hline Annonaceae & 42 & 5 & 19.79 \\
\hline Arecaceae & 32 & 4 & 14.26 \\
\hline Celastraceae & 9 & 1 & 14.15 \\
\hline Moraceae & 30 & 10 & 13.61 \\
\hline Myristicaceae & 25 & 8 & 11.13 \\
\hline Burseraceae & 20 & 11 & 10.39 \\
\hline Chrysobalanaceae & 19 & 11 & 9.29 \\
\hline Clusiaceae & 14 & 3 & 7.56 \\
\hline Euphorbiaceae & 11 & 5 & 7.42 \\
\hline Sapotaceae & 13 & 8 & 7.29 \\
\hline Lauraceae & 15 & 8 & 7.27 \\
\hline Sterculiaceae & 16 & 5 & 7.14 \\
\hline Rubiaceae & 14 & 3 & 6.80 \\
\hline Caryocaraceae & 5 & 2 & 6.42 \\
\hline Flacourtiaceae & 7 & 3 & 4.33 \\
\hline Simaroubaceae & 5 & 2 & 4.08 \\
\hline Vochysiaceae & 5 & 4 & 4.05 \\
\hline Apocynaceae & 7 & 4 & 3.72 \\
\hline Myrtaceae & 7 & 7 & 3.05 \\
\hline Boraginaceae & 5 & 5 & 2.96 \\
\hline Bignoniaceae & 2 & 1 & 2.66 \\
\hline Hugoniaceae & 4 & 1 & 2.63 \\
\hline Elaeocarpaceae & 5 & 4 & 2.48 \\
\hline Quiinaceae & 5 & 2 & 2.41 \\
\hline Araliaceae & 2 & 1 & 2.26 \\
\hline Bombacaceae & 4 & 2 & 1.58 \\
\hline Myrsinaceae & 1 & 1 & 1.46 \\
\hline Strelitziaceae & 3 & 1 & 1.34 \\
\hline Indet. & 3 & 3 & 1.34 \\
\hline Meliaceae & 2 & 2 & 1.05 \\
\hline Rosaceae & 2 & 1 & 0.92 \\
\hline Melastomataceae & 2 & 1 & 0.90 \\
\hline Tiliaceae & 1 & 1 & 0.83 \\
\hline
\end{tabular}


Tabela 2. Famílias listadas em ordem decrescente de valor de importância (VI), com número de indivíduos ( $N^{\circ}$ Ind.), número de espécies (No Spp.) encontradas na vila de Caicubi, Caracaraí, Roraima, Brasil.

\begin{tabular}{cccc}
\hline Família & $N^{\circ}$ Ind & $N^{\circ}$ Spp & (conclusão) \\
\hline Aquifoliaceae & 1 & 1 & 0.74 \\
Sapindaceae & 1 & 1 & 0.60 \\
Gnetaceae & 1 & 1 & 0.50 \\
Anacardiaceae & 1 & 1 & 0.50 \\
Dilliniaceae & 1 & 1 & 0.46 \\
Violaceae & 1 & 1 & 0.46 \\
Sabiaceae & 1 & 1 & 0.45 \\
Olacaceae & 1 & 1 & 0.44 \\
\hline
\end{tabular}

e 23,8\% da área basal. C. macrocarpa foi a espécie de maior VI pela sua abundância (39 indivíduos), tendo alcançado as maiores densidade e freqüência relativas. $C$. macrocarpa, árvore de porte médio, teve a variação na altura total de 8 a $28 \mathrm{~m}$ e sua altura média foi de $16 \mathrm{~m}$; o DAP variou de 10,2 a 37,9 cm e DAP médio de $20 \mathrm{~cm}$. Bocageopsis multiflora, Eschweilera coriacea e Euterpe precatoria, com 30, 21 e 20 indivíduos, respectivamente, também têm destaque por sua abundância e freqüência na área estudada. Entretanto, Goupia glabra, com nove indivíduos, e Cedrelinga cataeniformis, com apenas um indivíduo, têm valores baixos de densidade e freqüência relativas, apresentando os maiores valores de dominância relativa (DoR), 10,44\% e 7,55\%, respectivamente, o que as coloca entre as seis espécies de maiores VI. Este padrão também se repete para Caryocar glabrum subsp. parvifolium, com três indivíduos e DoR 4,26\%; Parkia nitida com três indivíduos e DoR 3,26\%; e Ormosia grossa com um indivíduo e DoR 3,98\%.

Além das quatro espécies de maiores populações (C. macrocarpa, B. multiflora, E. coriaceae e E. precatoria), as espécies Inga alba (15 indivíduos), Pourouma cf. tomentonsa supbsp. apiculata (15), Pourouma minor (13), Eschweilera pedicellata (12), Symphonia globulifera (12), Ferdinandusa rudgeoides (12) e Oenocarpus bacaba (10) apresentaram populações com mais de dez indivíduos e valores elevados na freqüência relativa.
Os 544 indivíduos amostrados, dentro dos parâmetros estabelecidos, somaram uma área basal de 26,35 $\mathrm{m}^{2}$. Pires e Prance (1985) citam que florestas densas podem ultrapassar $40 \mathrm{~m}^{2}$ de área basal e que florestas abertas encontram-se entre 18 a $24 \mathrm{~m}^{2}$. Os resultados indicam que se trata de uma floresta densa com uma baixa área basal aproximando-se de florestas abertas.

Na distribuição das árvores por classes de diâmetro (Figura 5), observa-se uma predominância de indivíduos (45,96\%) na classe diamétrica de 10-15 cm; 23,35\% dos indivíduos estão inseridos na classe de $>15-20 \mathrm{~cm} ; 10,85 \%$ na classe $>20-25 \mathrm{~cm} ; 6,6 \%$ na classe de $>25-30 ; 3,49 \%$ na classe de $>30-35 ; 3,3 \%$ na classe $>35-40$; os demais, totalizando 6,43\%, dividem-se em classes diamétricas acima de $40 \mathrm{~cm}$. O maior diâmetro foi de 159,15cm, encontrado no único indivíduo de Cedrelinga cataeniformis. O diâmetro médio foi $20,15 \mathrm{~cm}$, incluindo todos os indivíduos da amostragem; excluindo as lianas, o diâmetro foi $20,24 \mathrm{~cm}$. A curva formada pelos valores no conjunto de classes estabelecidas mostra a configuração de J invertido, demonstrando que há uma maior quantidade de indivíduos de menor porte e poucos indivíduos emergentes. Isto é esperado que ocorra com o incremento do diâmetro dos indivíduos, pois a distribuição de classes de tamanho é conseqüência da dinâmica da floresta, onde a quantidade de espaço constringe o número de árvores que podem se acomodar em um determinado tamanho de classe (Swaine, 1989). 


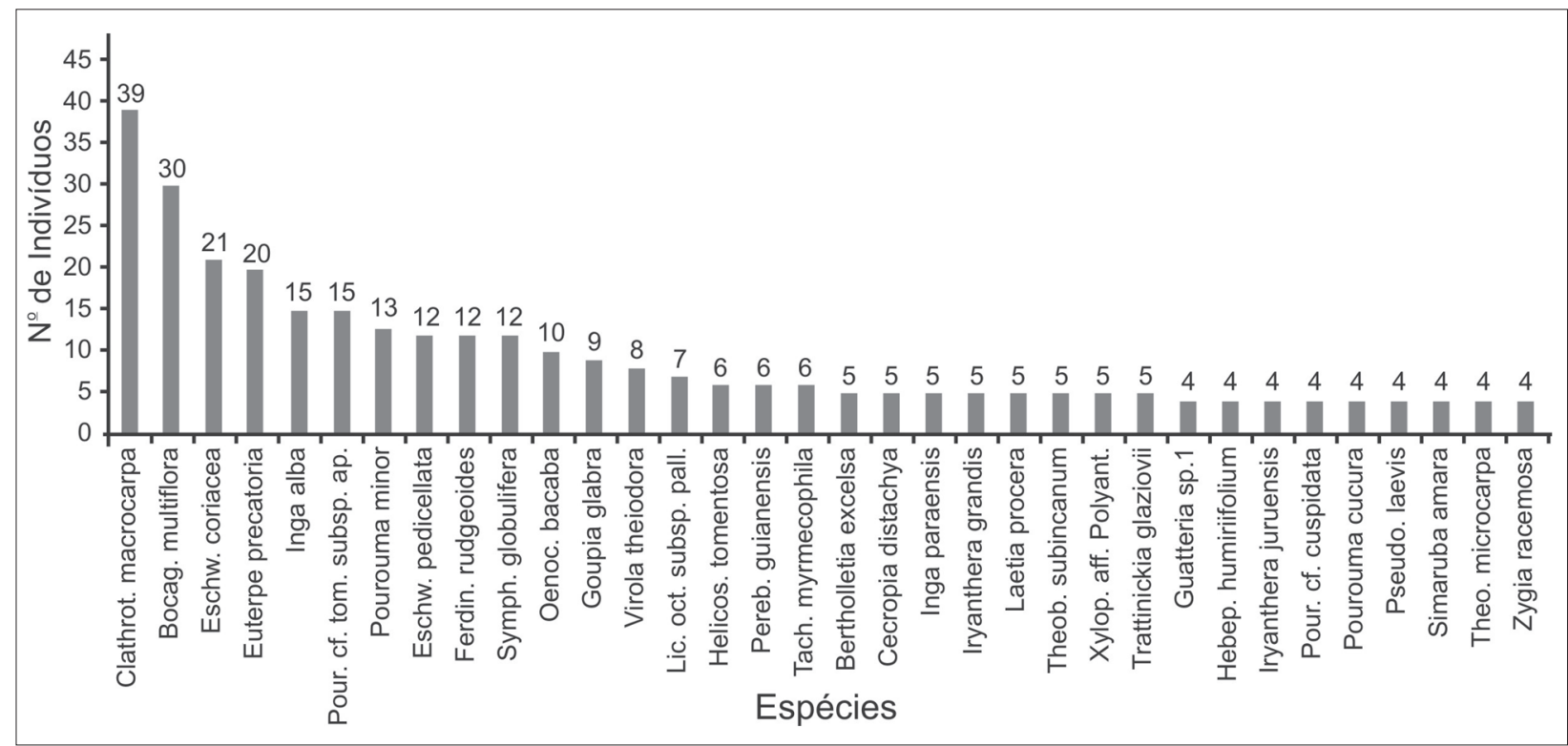

Figura 2. Número de indivíduos por espécies, amostrados pelo menos quatro vezes em um trecho de floresta de terra firme na vila de Caicubi, Caracaraí, Roraima, Brasil; 15 espécies foram amostradas três vezes; 39 duas vezes; 104 uma vez.

Tabela 3. Espécies amostradas na vila de Caicubi, Caracaraí, Roraima, Brasil e seus parâmetros fitossociológicos, em ordem decrescente de valor de importância. N - número de indivíduos; DR - densidade relativa; DA - densidade absoluta; DoR - dominância relativa; DoA - dominância absoluta; FR - freqüência relativa; FA - freqüência absoluta; VI - valor de importância.

\begin{tabular}{lcccccccc}
\hline ESPÉCIES & N & DA & DR & DoA & DoR & FA & FR & VI \\
\hline Clathrotropis macrocarpa & 39 & 39 & 7,17 & 1,40 & 5,29 & 33 & 6,41 & 18,87 \\
Goupia glabra & 9 & 9 & 1,65 & 2,75 & 10,44 & 9 & 1,75 & 13,84 \\
Bocageopsis multiflora & 30 & 30 & 5,51 & 0,69 & 2,62 & 26 & 5,05 & 13,18 \\
Eschweilera coriacea & 21 & 21 & 3,86 & 1,16 & 4,42 & 18 & 3,5 & 11,77 \\
Euterpe precatoria & 20 & 20 & 3,68 & 0,27 & 1,02 & 18 & 3,5 & 8,2 \\
Cedrelinga cataeniformis & 1 & 1 & 0,18 & 1,99 & 7,55 & 1 & 0,19 & 7,93 \\
Inga alba & 15 & 15 & 2,76 & 0,60 & 2,27 & 12 & 2,33 & 7,36 \\
Pourouma cf. tomentosa subsp. apiculata & 15 & 15 & 2,76 & 0,58 & 2,21 & 12 & 2,33 & 7,3 \\
Pourouma minor & 13 & 13 & 2,39 & 0,52 & 1,99 & 12 & 2,33 & 6,71 \\
Symphonia globulifera & 12 & 12 & 2,21 & 0,46 & 1,75 & 12 & 2,33 & 6,29 \\
Eschweilera pedicellata & 12 & 12 & 2,21 & 0,36 & 1,37 & 11 & 2,14 & 5,71 \\
Caryocar glabrum subsp. parviflorum & 3 & 3 & 0,55 & 1,12 & 4,26 & 3 & 0,58 & 5,4 \\
Ferdinandusa rudgeoides & 12 & 12 & 2,21 & 0,21 & 0,82 & 12 & 2,33 & 5,35 \\
Oenocarpus bacaba & 10 & 10 & 1,84 & 0,25 & 0,94 & 10 & 1,94 & 4,72 \\
Parkia nitida & 3 & 3 & 0,55 & 0,86 & 3,26 & 3 & 0,58 & 4,39 \\
Ormosia grossa & 1 & 1 & 0,18 & 1,05 & 3,98 & 1 & 0,19 & 4,36 \\
Bertholletia excelsa & 5 & 5 & 0,92 & 0,51 & 1,95 & 5 & 0,97 & 3,84 \\
\hline
\end{tabular}


Tabela 3. Espécies amostradas na vila de Caicubi, Caracaraí, Roraima, Brasil e seus parâmetros fitossociológicos, em ordem decrescente de valor de importância. N - número de indivíduos; DR - densidade relativa; DA - densidade absoluta; DoR - dominância relativa; DoA - dominância absoluta; FR - freqüência relativa; FA - freqüência absoluta; VI - valor de importância.

\begin{tabular}{|c|c|c|c|c|c|c|c|c|}
\hline ESPÉCIES & $N$ & DA & $\mathrm{DR}$ & DoA & DoR & FA & FR & $\mathrm{VI}$ \\
\hline Virola theiodora & 8 & 8 & 1,47 & 0,19 & 0,71 & 8 & 1,55 & 3,74 \\
\hline Simaruba amara & 4 & 4 & 0,74 & 0,52 & 1,96 & 4 & 0,78 & 3,48 \\
\hline Laetia procera & 5 & 5 & 0,92 & 0,36 & 1,37 & 5 & 0,97 & 3,26 \\
\hline Euphorbiaceae sp.1 & 3 & 3 & 0,55 & 0,52 & 1,97 & 3 & 0,58 & 3,1 \\
\hline Licania octandra subsp. pallida & 7 & 7 & 1,29 & 0,12 & 0,44 & 7 & 1,36 & 3,09 \\
\hline Trattinickia glaziovii & 5 & 5 & 0,92 & 0,30 & 1,12 & 5 & 0,97 & 3,01 \\
\hline Xylopia aff. Polyantha & 5 & 5 & 0,92 & 0,24 & 0,93 & 5 & 0,97 & 2,82 \\
\hline Helicostylis tomentosa & 6 & 6 & 1,1 & 0,11 & 0,42 & 6 & 1,17 & 2,69 \\
\hline Jacaranda copaia & 2 & 2 & 0,37 & 0,48 & 1,84 & 2 & 0,39 & 2,59 \\
\hline Guatteria sp.1 & 4 & 4 & 0,74 & 0,28 & 1,08 & 4 & 0,78 & 2,59 \\
\hline Perebea guianensis & 6 & 6 & 1,1 & 0,08 & 0,32 & 6 & 1,17 & 2,59 \\
\hline Cecropia distachya & 5 & 5 & 0,92 & 0,17 & 0,63 & 5 & 0,97 & 2,52 \\
\hline Hebepetalum humirifolium & 4 & 4 & 0,74 & 0,26 & 0,98 & 4 & 0,78 & 2,49 \\
\hline Tachigali myrmecophila & 6 & 6 & 1,1 & 0,10 & 0,38 & 5 & 0,97 & 2,45 \\
\hline Inga paraensis & 5 & 5 & 0,92 & 0,11 & 0,41 & 5 & 0,97 & 2,3 \\
\hline Iryanthera juruensis & 5 & 5 & 0,92 & 0,10 & 0,37 & 5 & 0,97 & 2,26 \\
\hline Schefflera morototoni & 2 & 2 & 0,37 & 0,38 & 1,44 & 2 & 0,39 & 2,2 \\
\hline Qualea paraensis & 1 & 1 & 0,18 & 0,47 & 1,8 & 1 & 0,19 & 2,18 \\
\hline Theobroma subincanum & 5 & 5 & 0,92 & 0,09 & 0,33 & 4 & 0,78 & 2,03 \\
\hline Theobroma microcarpa & 4 & 4 & 0,74 & 0,09 & 0,36 & 4 & 0,78 & 1,87 \\
\hline Iryanthera coriacea & 4 & 4 & 0,74 & 0,09 & 0,33 & 4 & 0,78 & 1,84 \\
\hline Couma guianensis & 3 & 3 & 0,55 & 0,17 & 0,64 & 3 & 0,58 & 1,77 \\
\hline Zygia racemosa & 4 & 4 & 0,74 & 0,07 & 0,25 & 4 & 0,78 & 1,76 \\
\hline Pseudolmedia laevis & 4 & 4 & 0,74 & 0,05 & 0,21 & 4 & 0,78 & 1,72 \\
\hline Pourouma melinonii subsp. melinonii & 2 & 2 & 0,37 & 0,25 & 0,95 & 2 & 0,39 & 1,71 \\
\hline Pourouma of. cuspidata & 4 & 4 & 0,74 & 0,05 & 0,19 & 4 & 0,78 & 1,7 \\
\hline Pourouma cucura & 4 & 4 & 0,74 & 0,04 & 0,17 & 3 & 0,58 & 1,49 \\
\hline Croton lanjouwensis & 3 & 3 & 0,55 & 0,13 & 0,51 & 2 & 0,39 & 1,45 \\
\hline Lecythis retusa & 2 & 2 & 0,37 & 0,18 & 0,67 & 2 & 0,39 & 1,43 \\
\hline Cybianthus aff. detergens & 1 & 1 & 0,18 & 0,28 & 1,05 & 1 & 0,19 & 1,43 \\
\hline Ocotea rhodophylla & 3 & 3 & 0,55 & 0,07 & 0,28 & 3 & 0,58 & 1,41 \\
\hline Aniba aff. Williamsii & 3 & 3 & 0,55 & 0,06 & 0,22 & 3 & 0,58 & 1,36 \\
\hline Ocotea nigrescens & 3 & 3 & 0,55 & 0,06 & 0,22 & 3 & 0,58 & 1,35 \\
\hline Sorocea guilleminiana & 3 & 3 & 0,55 & 0,05 & 0,21 & 3 & 0,58 & 1,34 \\
\hline Naucleopsis glabra & 3 & 3 & 0,55 & 0,05 & 0,2 & 3 & 0,58 & 1,33 \\
\hline
\end{tabular}


Tabela 3. Espécies amostradas na vila de Caicubi, Caracaraí, Roraima, Brasil e seus parâmetros fitossociológicos, em ordem decrescente de valor de importância. N - número de indivíduos; DR - densidade relativa; DA - densidade absoluta; DoR - dominância relativa; DoA - dominância absoluta; FR - freqüência relativa; FA - freqüência absoluta; VI - valor de importância.

\begin{tabular}{|c|c|c|c|c|c|c|c|c|}
\hline ESPÉCIES & $N$ & $\mathrm{DA}$ & $\mathrm{DR}$ & DoA & DoR & FA & $\mathrm{FR}$ & $\mathrm{VI}$ \\
\hline Quiina florida & 3 & 3 & 0,55 & 0,04 & 0,16 & 3 & 0,58 & 1,3 \\
\hline Sloanea rufa & 2 & 2 & 0,37 & 0,14 & 0,53 & 2 & 0,39 & 1,29 \\
\hline Crepidospermum of. rhoifolium & 3 & 3 & 0,55 & 0,04 & 0,14 & 3 & 0,58 & 1,27 \\
\hline Theobroma sylvestris & 3 & 3 & 0,55 & 0,04 & 0,13 & 3 & 0,58 & 1,27 \\
\hline Phenakospermum guyanense & 3 & 3 & 0,55 & 0,03 & 0,11 & 3 & 0,58 & 1,24 \\
\hline Alchornea triplinervia & 2 & 2 & 0,37 & 0,11 & 0,42 & 2 & 0,39 & 1,18 \\
\hline Moraceae sp.1 & 2 & 2 & 0,37 & 0,11 & 0,42 & 2 & 0,39 & 1,18 \\
\hline Clarisia racemosa & 2 & 2 & 0,37 & 0,11 & 0,41 & 2 & 0,39 & 1,17 \\
\hline Licania micrantha & 2 & 2 & 0,37 & 0,10 & 0,36 & 2 & 0,39 & 1,12 \\
\hline Perebea mollis subsp. mollis & 2 & 2 & 0,37 & 0,09 & 0,35 & 2 & 0,39 & 1,1 \\
\hline Sclerolobium setiferum & 1 & 1 & 0,18 & 0,19 & 0,73 & 1 & 0,19 & 1,1 \\
\hline Micropholis guyanensis subsp. guyanensis & 2 & 2 & 0,37 & 0,09 & 0,34 & 2 & 0,39 & 1,09 \\
\hline Sclerolobium aff. setiferum & 2 & 2 & 0,37 & 0,09 & 0,32 & 2 & 0,39 & 1,08 \\
\hline Quararibea ochrocalyx & 3 & 3 & 0,55 & 0,03 & 0,13 & 2 & 0,39 & 1,07 \\
\hline Pouteria caimito & 2 & 2 & 0,37 & 0,08 & 0,31 & 2 & 0,39 & 1,06 \\
\hline Xylopia amazonica & 2 & 2 & 0,37 & 0,07 & 0,28 & 2 & 0,39 & 1,04 \\
\hline Pouteria guianensis & 1 & 1 & 0,18 & 0,17 & 0,64 & 1 & 0,19 & 1,02 \\
\hline Alchornea schomburgkii & 2 & 2 & 0,37 & 0,06 & 0,25 & 2 & 0,39 & 1 \\
\hline Pouteria durlandii & 2 & 2 & 0,37 & 0,06 & 0,24 & 2 & 0,39 & 1 \\
\hline Protium hebetatum & 2 & 2 & 0,37 & 0,06 & 0,23 & 2 & 0,39 & 0,99 \\
\hline Touroulia guianensis & 2 & 2 & 0,37 & 0,05 & 0,18 & 2 & 0,39 & 0,94 \\
\hline Pouteria cuspidata & 2 & 2 & 0,37 & 0,05 & 0,18 & 2 & 0,39 & 0,94 \\
\hline Inga rhynchocalyx & 2 & 2 & 0,37 & 0,05 & 0,18 & 2 & 0,39 & 0,93 \\
\hline Cordia bicolor & 1 & 1 & 0,18 & 0,15 & 0,55 & 1 & 0,19 & 0,93 \\
\hline Licania hirsuta & 2 & 2 & 0,37 & 0,04 & 0,15 & 2 & 0,39 & 0,9 \\
\hline Lecythis zabucaja & 2 & 2 & 0,37 & 0,04 & 0,15 & 2 & 0,39 & 0,9 \\
\hline Licaria guianensis & 2 & 2 & 0,37 & 0,04 & 0,14 & 2 & 0,39 & 0,9 \\
\hline Virola venosa & 2 & 2 & 0,37 & 0,04 & 0,14 & 2 & 0,39 & 0,89 \\
\hline Pourouma villosa & 2 & 2 & 0,37 & 0,03 & 0,12 & 2 & 0,39 & 0,88 \\
\hline Protium opacum subsp. opacum & 2 & 2 & 0,37 & 0,03 & 0,12 & 2 & 0,39 & 0,87 \\
\hline Theobroma obovatum & 2 & 2 & 0,37 & 0,03 & 0,11 & 2 & 0,39 & 0,87 \\
\hline Dicorynia paraensis & 1 & 1 & 0,18 & 0,13 & 0,48 & 1 & 0,19 & 0,86 \\
\hline Stryphnodendrom paniculatum & 2 & 2 & 0,37 & 0,03 & 0,1 & 2 & 0,39 & 0,86 \\
\hline Caryocar glabrum & 2 & 2 & 0,37 & 0,03 & 0,1 & 2 & 0,39 & 0,86 \\
\hline Prunus myrtifolia & 2 & 2 & 0,37 & 0,02 & 0,09 & 2 & 0,39 & 0,85 \\
\hline
\end{tabular}


Tabela 3. Espécies amostradas na vila de Caicubi, Caracaraí, Roraima, Brasil e seus parâmetros fitossociológicos, em ordem decrescente de valor de importância. N - número de indivíduos; DR - densidade relativa; DA - densidade absoluta; DoR - dominância relativa; DoA - dominância absoluta; FR - freqüência relativa; FA - freqüência absoluta; VI - valor de importância.

\begin{tabular}{|c|c|c|c|c|c|c|c|c|}
\hline ESPÉCIES & $N$ & DA & $\mathrm{DR}$ & DoA & DoR & FA & FR & VI \\
\hline Pouteria glomerata & 2 & 2 & 0,37 & 0,02 & 0,09 & 2 & 0,39 & 0,84 \\
\hline Inga grandiflora & 2 & 2 & 0,37 & 0,02 & 0,08 & 2 & 0,39 & 0,84 \\
\hline Protium grandifolium & 2 & 2 & 0,37 & 0,02 & 0,08 & 2 & 0,39 & 0,83 \\
\hline Theobroma speciosa & 2 & 2 & 0,37 & 0,02 & 0,07 & 2 & 0,39 & 0,83 \\
\hline Miconia traillii & 2 & 2 & 0,37 & 0,02 & 0,07 & 2 & 0,39 & 0,83 \\
\hline Ambelania acida & 2 & 2 & 0,37 & 0,02 & 0,07 & 2 & 0,39 & 0,82 \\
\hline Vochysia vismiaefolia & 2 & 2 & 0,37 & 0,02 & 0,06 & 2 & 0,39 & 0,82 \\
\hline Virola calophylla & 2 & 2 & 0,37 & 0,02 & 0,06 & 2 & 0,39 & 0,82 \\
\hline Protium amazonicum & 1 & 1 & 0,18 & 0,11 & 0,42 & 1 & 0,19 & 0,8 \\
\hline Apeiba echinata & 1 & 1 & 0,18 & 0,11 & 0,42 & 1 & 0,19 & 0,8 \\
\hline Osteophloeum platyspermum & 2 & 2 & 0,37 & 0,05 & 0,2 & 1 & 0,19 & 0,76 \\
\hline Virola enlongata & 1 & 1 & 0,18 & 0,09 & 0,36 & 1 & 0,19 & 0,74 \\
\hline Ilex divaricata & 1 & 1 & 0,18 & 0,09 & 0,33 & 1 & 0,19 & 0,71 \\
\hline Couepia aff. obovata & 1 & 1 & 0,18 & 0,07 & 0,28 & 1 & 0,19 & 0,66 \\
\hline Eschweilera grandiflora & 1 & 1 & 0,18 & 0,07 & 0,26 & 1 & 0,19 & 0,64 \\
\hline Tovomita schomburgkii & 1 & 1 & 0,18 & 0,06 & 0,25 & 1 & 0,19 & 0,62 \\
\hline Hieronyma mollis & 1 & 1 & 0,18 & 0,05 & 0,2 & 1 & 0,19 & 0,58 \\
\hline Attalea maripa & 1 & 1 & 0,18 & 0,05 & 0,2 & 1 & 0,19 & 0,58 \\
\hline Parkia cf. decussata & 1 & 1 & 0,18 & 0,05 & 0,19 & 1 & 0,19 & 0,57 \\
\hline Cupania scrobiculata & 1 & 1 & 0,18 & 0,05 & 0,19 & 1 & 0,19 & 0,57 \\
\hline Ferdinandusa sp.1 & 1 & 1 & 0,18 & 0,05 & 0,19 & 1 & 0,19 & 0,57 \\
\hline Pourouma guianensis subsp. guianensis & 1 & 1 & 0,18 & 0,05 & 0,19 & 1 & 0,19 & 0,57 \\
\hline Pourouma tomentosa subsp. tomentosa & 1 & 1 & 0,18 & 0,05 & 0,18 & 1 & 0,19 & 0,56 \\
\hline Guarea guidonia & 1 & 1 & 0,18 & 0,04 & 0,17 & 1 & 0,19 & 0,55 \\
\hline Hirtella racemosa var. hexandra & 1 & 1 & 0,18 & 0,04 & 0,14 & 1 & 0,19 & 0,52 \\
\hline Cordia panicularis & 1 & 1 & 0,18 & 0,04 & 0,14 & 1 & 0,19 & 0,52 \\
\hline Cordia sp. & 1 & 1 & 0,18 & 0,04 & 0,14 & 1 & 0,19 & 0,52 \\
\hline Inga of. laurina & 1 & 1 & 0,18 & 0,04 & 0,14 & 1 & 0,19 & 0,51 \\
\hline Swartzia cf. dolichopoda & 1 & 1 & 0,18 & 0,04 & 0,14 & 1 & 0,19 & 0,51 \\
\hline Andira micrantha & 1 & 1 & 0,18 & 0,04 & 0,13 & 1 & 0,19 & 0,51 \\
\hline Lecythis poiteaui & 1 & 1 & 0,18 & 0,03 & 0,13 & 1 & 0,19 & 0,51 \\
\hline Pseudopiptadenia psilostachya & 1 & 1 & 0,18 & 0,03 & 0,12 & 1 & 0,19 & 0,5 \\
\hline Enterolobium schomburgkii & 1 & 1 & 0,18 & 0,03 & 0,12 & 1 & 0,19 & 0,49 \\
\hline Myrcia aff. Rufipila & 1 & 1 & 0,18 & 0,03 & 0,11 & 1 & 0,19 & 0,49 \\
\hline Protium trifoliolatum & 1 & 1 & 0,18 & 0,03 & 0,11 & 1 & 0,19 & 0,48 \\
\hline
\end{tabular}


Tabela 3. Espécies amostradas na vila de Caicubi, Caracaraí, Roraima, Brasil e seus parâmetros fitossociológicos, em ordem decrescente de valor de importância. N - número de indivíduos; DR - densidade relativa; DA - densidade absoluta; DoR - dominância relativa; DoA - dominância absoluta; FR - freqüência relativa; FA - freqüência absoluta; VI - valor de importância.

\begin{tabular}{|c|c|c|c|c|c|c|c|c|}
\hline ESPÉCIES & $N$ & $\mathrm{DA}$ & DR & DoA & DoR & FA & $\mathrm{FR}$ & $\mathrm{VI}$ \\
\hline Pourouma ovata & 1 & 1 & 0,18 & 0,03 & 0,1 & 1 & 0,19 & 0,48 \\
\hline Pleurothyrium vasquezii & 1 & 1 & 0,18 & 0,03 & 0,1 & 1 & 0,19 & 0,48 \\
\hline Eschweilera bracteosa & 1 & 1 & 0,18 & 0,03 & 0,1 & 1 & 0,19 & 0,48 \\
\hline Fusaea longifolia & 1 & 1 & 0,18 & 0,03 & 0,1 & 1 & 0,19 & 0,48 \\
\hline Odontadenia cognata & 1 & 1 & 0,18 & 0,03 & 0,1 & 1 & 0,19 & 0,47 \\
\hline Sclerolobium chrysophyllum & 1 & 1 & 0,18 & 0,03 & 0,09 & 1 & 0,19 & 0,47 \\
\hline Eugenia aff. florida & 1 & 1 & 0,18 & 0,02 & 0,09 & 1 & 0,19 & 0,47 \\
\hline Licania sothersiae & 1 & 1 & 0,18 & 0,02 & 0,09 & 1 & 0,19 & 0,47 \\
\hline Gnetum leyboldii & 1 & 1 & 0,18 & 0,02 & 0,09 & 1 & 0,19 & 0,47 \\
\hline Tapirira guianensis & 1 & 1 & 0,18 & 0,02 & 0,09 & 1 & 0,19 & 0,46 \\
\hline Erisma bracteosum & 1 & 1 & 0,18 & 0,02 & 0,08 & 1 & 0,19 & 0,46 \\
\hline Pouteria sp.1 & 1 & 1 & 0,18 & 0,02 & 0,08 & 1 & 0,19 & 0,46 \\
\hline Astrocaryum aculeatum & 1 & 1 & 0,18 & 0,02 & 0,07 & 1 & 0,19 & 0,44 \\
\hline Helianthostylis sprucei & 1 & 1 & 0,18 & 0,02 & 0,06 & 1 & 0,19 & 0,44 \\
\hline Simaba polyphylla & 1 & 1 & 0,18 & 0,02 & 0,06 & 1 & 0,19 & 0,44 \\
\hline Dacryodes sclerophylla & 1 & 1 & 0,18 & 0,01 & 0,06 & 1 & 0,19 & 0,43 \\
\hline Pourouma ferruginea & 1 & 1 & 0,18 & 0,01 & 0,06 & 1 & 0,19 & 0,43 \\
\hline Chrysophyllum sanguinolentum & 1 & 1 & 0,18 & 0,01 & 0,06 & 1 & 0,19 & 0,43 \\
\hline Guarea silvatica & 1 & 1 & 0,18 & 0,01 & 0,06 & 1 & 0,19 & 0,43 \\
\hline Inga umbratica & 1 & 1 & 0,18 & 0,01 & 0,05 & 1 & 0,19 & 0,43 \\
\hline Laetia sp.1 & 1 & 1 & 0,18 & 0,01 & 0,05 & 1 & 0,19 & 0,43 \\
\hline Inga thibaudiana & 1 & 1 & 0,18 & 0,01 & 0,05 & 1 & 0,19 & 0,43 \\
\hline Licania heteromorpha subsp. heteromorpha & 1 & 1 & 0,18 & 0,01 & 0,05 & 1 & 0,19 & 0,43 \\
\hline Sloanea cf. synandra & 1 & 1 & 0,18 & 0,01 & 0,05 & 1 & 0,19 & 0,43 \\
\hline Licania canescens & 1 & 1 & 0,18 & 0,01 & 0,05 & 1 & 0,19 & 0,43 \\
\hline Tachigali venusta & 1 & 1 & 0,18 & 0,01 & 0,05 & 1 & 0,19 & 0,43 \\
\hline Protium subserratum & 1 & 1 & 0,18 & 0,01 & 0,05 & 1 & 0,19 & 0,43 \\
\hline Pterocarpus officinalis & 1 & 1 & 0,18 & 0,01 & 0,05 & 1 & 0,19 & 0,43 \\
\hline Inga aff. Bicoloriflora & 1 & 1 & 0,18 & 0,01 & 0,05 & 1 & 0,19 & 0,43 \\
\hline Coussapoa sprucei & 1 & 1 & 0,18 & 0,01 & 0,05 & 1 & 0,19 & 0,43 \\
\hline Pinzona coriacea & 1 & 1 & 0,18 & 0,01 & 0,05 & 1 & 0,19 & 0,43 \\
\hline Licania unguiculata & 1 & 1 & 0,18 & 0,01 & 0,05 & 1 & 0,19 & 0,42 \\
\hline Paypayrola sp. & 1 & 1 & 0,18 & 0,01 & 0,05 & 1 & 0,19 & 0,42 \\
\hline Ormosia aff. nobilis var. nobilis & 1 & 1 & 0,18 & 0,01 & 0,05 & 1 & 0,19 & 0,42 \\
\hline Eugenia sp.1 & 1 & 1 & 0,18 & 0,01 & 0,05 & 1 & 0,19 & 0,42 \\
\hline
\end{tabular}


Tabela 3. Espécies amostradas na vila de Caicubi, Caracaraí, Roraima, Brasil e seus parâmetros fitossociológicos, em ordem decrescente de valor de importância. N - número de indivíduos; DR - densidade relativa; DA - densidade absoluta; DoR - dominância relativa; DoA - dominância absoluta; FR - freqüência relativa; FA - freqüência absoluta; VI - valor de importância.

\begin{tabular}{|c|c|c|c|c|c|c|c|c|}
\hline ESPÉCIES & $N$ & DA & $\mathrm{DR}$ & DoA & DoR & FA & FR & VI \\
\hline Trattinickia boliviana & 1 & 1 & 0,18 & 0,01 & 0,05 & 1 & 0,19 & 0,42 \\
\hline Ocotea subterminalis & 1 & 1 & 0,18 & 0,01 & 0,05 & 1 & 0,19 & 0,42 \\
\hline Calycolpus sp. & 1 & 1 & 0,18 & 0,01 & 0,05 & 1 & 0,19 & 0,42 \\
\hline Licania cf. prismatocarpa & 1 & 1 & 0,18 & 0,01 & 0,05 & 1 & 0,19 & 0,42 \\
\hline Qualea sp.1 & 1 & 1 & 0,18 & 0,01 & 0,04 & 1 & 0,19 & 0,42 \\
\hline Ocotea sp.E & 1 & 1 & 0,18 & 0,01 & 0,04 & 1 & 0,19 & 0,42 \\
\hline Cordia exaltata & 1 & 1 & 0,18 & 0,01 & 0,04 & 1 & 0,19 & 0,42 \\
\hline Indet. sp.3 & 1 & 1 & 0,18 & 0,01 & 0,04 & 1 & 0,19 & 0,42 \\
\hline Pourouma tomentosa subsp. Essequiboensis & 1 & 1 & 0,18 & 0,01 & 0,04 & 1 & 0,19 & 0,42 \\
\hline Ophiocaryon aff. manausense & 1 & 1 & 0,18 & 0,01 & 0,04 & 1 & 0,19 & 0,42 \\
\hline Rhigospira quadrangularis & 1 & 1 & 0,18 & 0,01 & 0,04 & 1 & 0,19 & 0,42 \\
\hline Indet. sp.2 & 1 & 1 & 0,18 & 0,01 & 0,04 & 1 & 0,19 & 0,42 \\
\hline Myrcia sylvatica & 1 & 1 & 0,18 & 0,01 & 0,04 & 1 & 0,19 & 0,42 \\
\hline Gustavia augusta & 1 & 1 & 0,18 & 0,01 & 0,04 & 1 & 0,19 & 0,41 \\
\hline Maquira sclerophylla & 1 & 1 & 0,18 & 0,01 & 0,04 & 1 & 0,19 & 0,41 \\
\hline Sloanea pubescens & 1 & 1 & 0,18 & 0,01 & 0,04 & 1 & 0,19 & 0,41 \\
\hline Swartzia corrugata & 1 & 1 & 0,18 & 0,01 & 0,04 & 1 & 0,19 & 0,41 \\
\hline Mezilaurus subcordata & 1 & 1 & 0,18 & 0,01 & 0,03 & 1 & 0,19 & 0,41 \\
\hline Licania caudata & 1 & 1 & 0,18 & 0,01 & 0,03 & 1 & 0,19 & 0,41 \\
\hline Dacryodes cf. hopkinsii & 1 & 1 & 0,18 & 0,01 & 0,03 & 1 & 0,19 & 0,41 \\
\hline Borojoa claviflora & 1 & 1 & 0,18 & 0,01 & 0,03 & 1 & 0,19 & 0,41 \\
\hline Bahuinia guianensis & 1 & 1 & 0,18 & 0,01 & 0,03 & 1 & 0,19 & 0,41 \\
\hline Clusia grandiflora & 1 & 1 & 0,18 & 0,01 & 0,03 & 1 & 0,19 & 0,41 \\
\hline Inga aff. capitata & 1 & 1 & 0,18 & 0,01 & 0,03 & 1 & 0,19 & 0,41 \\
\hline Lindackeria of. paludosa & 1 & 1 & 0,18 & 0,01 & 0,03 & 1 & 0,19 & 0,41 \\
\hline Eugenia cf. omissa & 1 & 1 & 0,18 & 0,01 & 0,03 & 1 & 0,19 & 0,41 \\
\hline Eugenia of. cuspidifolia & 1 & 1 & 0,18 & 0,01 & 0,03 & 1 & 0,19 & 0,41 \\
\hline Dinizia excelsa & 1 & 1 & 0,18 & 0,01 & 0,03 & 1 & 0,19 & 0,41 \\
\hline Rhodognaphalopsis cf. duckei & 1 & 1 & 0,18 & 0,01 & 0,03 & 1 & 0,19 & 0,41 \\
\hline Indet. sp.1 & 1 & 1 & 0,18 & 0,01 & 0,03 & 1 & 0,19 & 0,41 \\
\hline Iryanthera grandis & 1 & 1 & 0,18 & 0,01 & 0,03 & 1 & 0,19 & 0,41 \\
\hline Leg: Papilionoideae sp.1 & 1 & 1 & 0,18 & 0,01 & 0,03 & 1 & 0,19 & 0,41 \\
\hline Cordia nodosa & 1 & 1 & 0,18 & 0,01 & 0,03 & 1 & 0,19 & 0,41 \\
\hline Minquartia guianensis & 1 & 1 & 0,18 & 0,01 & 0,03 & 1 & 0,19 & 0,41 \\
\hline Sloanea sp.1 & 1 & 1 & 0,18 & 0,01 & 0,03 & 1 & 0,19 & 0,41 \\
\hline
\end{tabular}


Agruparam-se os indivíduos amostrados em 12 classes de altura (Figura 6), variando a amplitude de alturas entre 3 a $58 \mathrm{~m}$. O maior número de indivíduos concentrou-se na segunda $(31,25 \%)$ e terceira classes $(30,15 \%)$. A classe de maior altura apresentou apenas um indivíduo de Ormosia grossa, representada na área por esse único indivíduo. O pequeno número de amostras na primeira classe deveu-se ao fato de várias árvores desta classe apresentarem a copa quebrada (o que diminuiu a sua altura total), e $46 \%$ dos indivíduos desta classe possuírem alturas de $7 \mathrm{~m}$, encontrando-se próximo à altura da segunda classe (>7-12 $\mathrm{m})$. A altura média encontrada foi de 16,41 m (excluindo as lianas), sendo as árvores emergentes, indivíduos de Ormosia grossa (58 m de altura), Jacaranda copaia (48 m), Laetia procera (48 m) e Cedrelinga cataeniformis (47 m). J. copaia e $L$. procera estavam representadas por dois e cinco indivíduos, respectivamente, e as duas outras espécies por apenas um indivíduo.

Na Vila de Maré (61015'W, 1045”S), em terras Waimiri Atroari, Milliken (1998) inventariou 1 ha de floresta de terra firme, utilizando método de parcela e incluindo indivíduos com $D A P \geq 10 \mathrm{~cm}$, sendo esta a área mais próxima àquela estudada em Caicubi. Encontrou 662 indivíduos, em 216 espécies e 41 famílias das quais 17 lianas em 14 espécies e oito famílias. O número de espécies e de famílias foi aproximado ao encontrado no presente estudo. O número de indivíduos, porém, foi maior (Tabela 4).

Ao comparar as dez familias com maior VI apresentadas por Milliken (1998) com àquelas do presente estudo, sete delas são comuns, sendo Leguminosae a de maior VI em ambas as áreas. As demais aparecem em diferentes ordenações. Em relação às espécies, Cathrotropis macrocarpa é a de maior VI nas duas áreas: em Vila de Maré apresentou VI de 24,7 e 72 indivíduos; em Caicubi apresentou VI de 18,87 e 39 indivíduos. Eschweilera coriacea é a segunda espécie de maior VI em Vila de Maré (VI de 18,2 e 53 indivíduos) e é a quarta de maior VI em Caicubi (VI de 11,77 e 21 indivíduos). Além destas duas espécies, não há outras comuns entre as dez espécies de maior VI, em ambas as áreas. Dentre as dez de maior VI da área de Vila de Maré, quatro não foram amostradas em Caicubi. Na Tabela 4 estão sintetizados os dados de Vila de Maré e de outros dois estudos realizados na Amazônia Central e Sudeste.

Ferreira e Prance (1999) amostraram 3 ha de floresta alta no Parque Nacional Jaú (10 90'-3 00'S, $61^{\circ}$ $\left.25^{\prime}-63^{\circ} 50^{\prime} \mathrm{W}\right)$, usando DAP $\geq 10 \mathrm{~cm}$. Encontraram uma média de 146,7 espécies/hectare e densidade média de 673,7 árvores/hectare; o mais rico apresentou 159 espécies e o de maior densidade apresentou 713 indivíduos. Em dois dos hectares por eles amostrados, cinco das famílias de maiores VI estão incluídas entre as dez de maiores VI em Caicubi (Leguminosae por eles tratada em três famílias). No outro hectare, são seis famílias que estão entre as dez de maiores VI em Caicubi. Escweilera coriacea é a única espécie comum entre as dez de maiores VI entre um dos hectares estudados por Ferreira e Prance (1999) e em Caicubi. Esta também é a única espécie comum entre as dez de maiores VI entre o estudo de Milliken (1998) e de Ferreira e Prance (1999). Os outros dois hectares, de Ferreira e Prance (1999), não possuem espécies em comum com Caicubi, quando se observam as dez espécies de maiores VI (Tabelas 5 e 6).

Campbell et al. (1986), em 'O Deserto', no rio Xingu, Pará (3 29' S/ 510 40’ W), amostraram 3 ha de floresta de terra firme, utilizando também como critério de inclusão DAP $\geq 10 \mathrm{~cm}$. Encontraram 393, 567 e 460 indivíduos em cada um dos hectares estudados; 133, 162 e 118 espécies, respectivamente; e 33 famílias nos três hectares estudados. Das dez famílias com maiores VI, cinco estão entre as dez de maiores VI em Caicubi. Nenhuma espécie, entre as 10 de maiores $\mathrm{VI}$, é comum ao trecho estudado em Caicubi (Tabelas 5 e 6).

Boom (1986), em Beni, Bolívia (11045'S, 6602 'W), amostrou 1 ha de floresta de terra firme, utilizando um $\mathrm{DAP} \geq 10 \mathrm{~cm}$. Encontrou 649 indivíudos, 94 espécies e 28 famílias. Das dez famílias com maiores VI, sete estão entre as dez de maiores VI em Caicubi, mas não há espécie em comum entre as dez de maiores VI (Tabelas 5 e 6). 


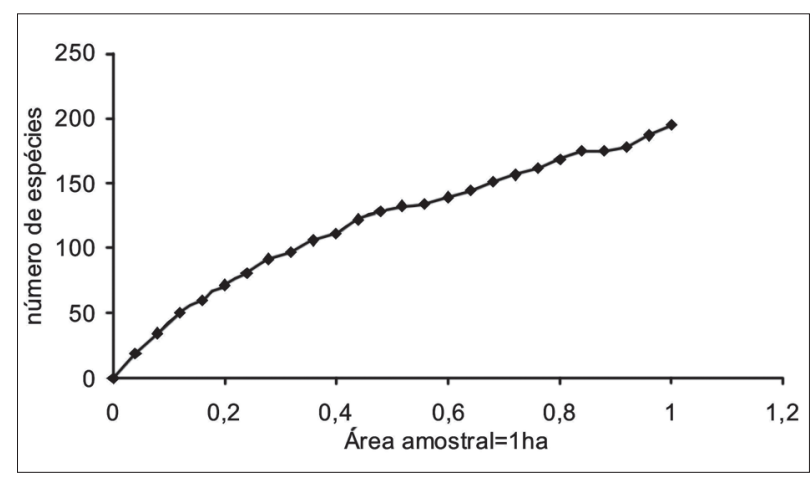

Figura 3. Curva do número de espécies em relação às parcelas amostradas em um trecho de floresta de terra firme na vila de Caicubi, Caracaraí, Roraima, Brasil.

Os dados encontrados em Caicubi e nos quatro últimos trabalhos citados corroboram com Nelson e Oliveira (2001), quando afirmam que a composição das florestas amazônicas varia em função de sua fisionomia e da distância entre sítios amostrados, e trazem aporte de dados para a confirmação da hipótese de que a floresta de terra firme é um mosaico de florestas com variada composição e estrutura.

A família Leguminosae, quando considerada como um só táxon, é, de modo geral, a de mais destaque em importância fitossociológica nos estudos citados, excetuando Boom (1986), que encontrou Moraceae como a família dominante. A família Leguminosae também é apontada como de grande importância em outros estudos realizados na Amazônia (Nelson; Oliveira, 2001). Entretanto, em relação a espécies, não há nenhuma que possa ser considerada como de destaque no conjunto de trechos estudados, o que corrobora com Campbel et al. (1986) quando afirmam que a Amazônia é um grande mosaico de florestas, e com Campbel et al. (1986) e Nelson e Oliveira (2001), quando alertam para ter cuidado ao se tentar fazer generalizações para a Amazônia a partir de dados florísticos e estruturais oriundos de amostras pontuais.

A família Lecythidaceae alcança sua maior expressão nas florestas de terra firme da Amazônia e a presença de muitas espécies dessa família pode ser considerada como indicadora de florestas preservadas (Mori, 2001). Os dados encontrados em Caicubi comprovam este fato. Foram encontradas nove espécies de árvores desta família, uma delas representadas por 21 indivíduos (Eschweilera coriacea), uma por 12 indivíduos (E. pedicellata), uma com cinco indivíduos (Bertholetia excelsa), duas com dois e quatro por apenas um indivíduo. E. coriacea é uma espécie comum e de distribuição ampla na Amazônia e apontada entre as espécies com destaque em diversos inventários (Salomão et al., 1988; Ferreira; Prance, 1999; Milliken, 1998), sendo a quarta espécie em VI no trecho estudado.

Tabela 4. Número de indivíduos, espécies, gêneros, famílias e área basal encontrados em quatro estudos fitossociológicos realizados em trechos de 1 ha de florestas de terra firme na Amazônia, tendo como critério de inclusão indivíduos com DAP $\geq 10 \mathrm{~cm}$ (**** incluindo lianas).

\begin{tabular}{lccccc}
\hline \multicolumn{1}{r}{ Trabalhos } & No Ind & Espécies & Gêneros & Famílias & A. Basal Tot. \\
\hline Boom (1986) & 649 & 94 & 62 & 28 & 21,48 \\
Campbell et al. (1986) (1) & 393 & 133 & 76 & 33 & 27,63 \\
Campbell et al. (1986) (2) & 567 & 162 & 83 & 33 & 32,14 \\
Campbell et al. (1986) (3) & 46 & 118 & 72 & 33 & 28,68 \\
Ferreira e Prance (1999) (1) & 639 & 144 & & 36 & 32,8 \\
Ferreira e Prance (1999) (2) & 669 & 159 & & 41 & 37,8 \\
Ferreira e Prance (1999) (3) & 713 & 137 & & 37 & 40,2 \\
Milliken (1998)**** & 662 & 216 & $\geq 109$ & 41 & ca 31 \\
Nosso estudo**** & 544 & 194 & 68 & 43 & 26,353 \\
\hline
\end{tabular}

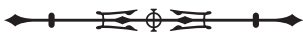




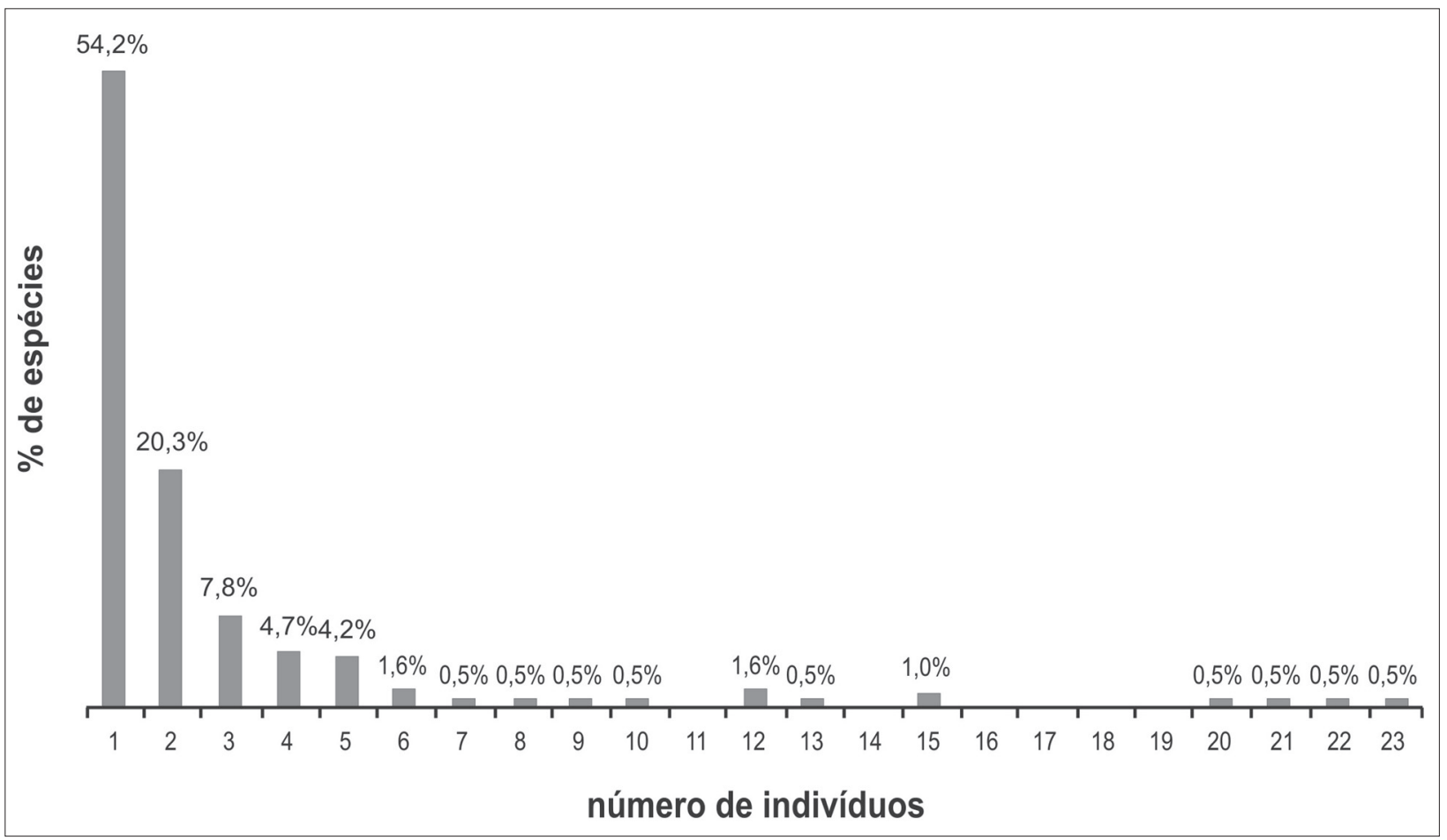

Figura 4. Porcentagem de espécies em relação ao de número de indivíduos amostrados em um trecho de floresta de terra firme na vila de Caicubi, Caracaraí, Roraima, Brasil (* a classe 22 corresponde a 30 indivíduos amostrados; e a classe 23, a 39 indivíduos amostrados).

Em Caicubi, Cecropiaceae foi a segunda família de maior VI. Das 13 espécies amostradas, 11 pertencem ao gênero Pourouma, uma a Coussapoua e uma espécie de Cecropia. Cecropiaceae não aparece como família de destaque no trecho estudado por Milliken (1998), embora seja este o trecho mais próximo de Caicubi. $\bigcirc$ mesmo ocorre nos trechos estudados por Campbel et al. (1986). Em Ferreira e Prance (1999) não ocorre com destaque em um dos trechos e é a décima em VI nos outros dois trechos estudados por estes autores.

\section{CONCLUSÃO}

O trecho estudado na vila de Caicubi, Caracarí, Roraima, em termos de estrutura, diversidade e composição florística, dentro dos limites estabelecidos pela metodologia utilizada, corrobora com as características estruturais apontadas por diferentes autores para as florestas de terra firme da Amazônia. As famílias mais importantes no estudo realizado são, de modo geral, aquelas encontradas em outros trabalhos realizados na Amazônia, sendo elas Leguminosae, Cecropiaceae, Lecythidaceae, Annonaceae, Arecaceae, Moraceae, Myristicaceae, Burseraceae, Chrysobalanaceae, Sapotaceae e Lauraceae. A importância particular das Leguminosas, encontradas no trecho estudado, parece ser uma característica de florestas de terra firme da Amazônia, especialmente daquelas na bacia do rio Negro.

Entretanto, a composição de espécies encontradas difere substancialmente de outros inventários conduzidos na Amazônia, corroborando com as premissas de que a floresta de terra firme é um mosaico de florestas. Assim, embora os inventários em áreas de 1 ha, no contexto da Amazônia, não pareçam adequados para mostrar toda a diversidade de espécies, como apontado pela curva espécie/área, estudos em áreas deste tamanho podem espelhar a riqueza de espécies e as diferenças em composição de espécies de distintos trechos de floresta de terra firme. 
Tabela 5. Famílias com maiores VI entre estudos realizados em trechos de 1 ha de floresta de terra firme na Amazônia, tendo como critério de inclusão indivíduos com DAP $\geq 10 \mathrm{~cm}$.

\begin{tabular}{|c|c|c|c|c|c|c|}
\hline $\begin{array}{l}\text { presente } \\
\text { estudo }\end{array}$ & Milliken (1998) & $\begin{array}{c}\text { Ferreira e } \\
\text { Prance (1999) } \\
\text { (Hectare 1) }\end{array}$ & $\begin{array}{c}\text { Ferreira e } \\
\text { Prance (1999) } \\
\text { (Hectare 2) }\end{array}$ & $\begin{array}{c}\text { Ferreira e } \\
\text { Prance (1999) } \\
\text { (Hectare 3) }\end{array}$ & $\begin{array}{c}\text { Campbell et al. } \\
\text { (1986) }\end{array}$ & Boom (1986) \\
\hline Leguminosae & Leguminosae & Chrysobalanaceae & Myristicaceae & Lecythidaceae & Leguminosae & Moraceae \\
\hline Cecropiaceae & Lecytidaceae & Myristicaceae & Burseraceae & Myristicaceae & Arecaceae & Myristicaceae \\
\hline Lecythidaceae & Sapotaceae & Bombacaceae & Leguminosae & Leguminosae & Lecythidaceae & Arecaceae \\
\hline Annonaceae & Burseraceae & Burseraceae & Bombacaceae & Lauraceae & Moraceae & Leguminosae \\
\hline Arecaceae & Moraceae & Leguminosae & Lauraceae & Burseraceae & Bombacaceae & Melastomataceae \\
\hline Celastraceae & Lauraceae & Sapotaceae & Lecythidaceae & Leguminosae & Meliaceae & Cecropiaceae \\
\hline Moraceae & Chrysobalanaceae & Euphorbiaceae & Euphorbiaceae & Chrysobalanaceae & Sterculiaceae & Vochysiaceae \\
\hline Myristicaceae & Myristicaceae & Lauraceae & Leguminosae & Sapotaceae & Nyctaginaceae & Annonaceae \\
\hline Burseraceae & Meliaceae & Lecythidaceae & Cecropiaceae & Bombacaceae & Chrysobalanaceae & Chrysobalanaceae \\
\hline Chrysobalanaceae & Annonaceae & Cecropiaceae & Combretaceae & Euphorbiaceae & Sapotaceae & Rubiaceae \\
\hline
\end{tabular}

Devido a diferenças em metodologias aplicadas em inventários na floresta de terra firme da Amazônia, é difícil fazer comparações entre resultados encontrados por diferentes autores que estudaram estas florestas. Listagens completas de espécies, seus exemplares de referência e tabelas contendo dados de estrutura são essenciais para a comparação entre os trabalhos, possibilitando conclusões mais abrangentes sobre estas florestas.

\section{AGRADECIMENTOS}

Ao instituto Caiuá, por financiar o projeto, e principalmente a Walo Leuzinger, por ter acreditado em nosso trabalho. À comunidade Caicubi, pela acolhida carinhosa, em especial a Ernane Fontes Barbosa, pela ajuda e dedicação ao campo. A C.A. Cid Ferreira, pelo inestimável apoio no herbário do INPA, bem como a Paulo Assunção, pelo auxílio na confirmação das identificações neste mesmo herbário. Aos especialistas Alberto Vicentini, Douglas Daly, José Eduardo Ribeiro, Michael Hopkins pela identificação de espécies de famílias de suas especialidades. A Rejan Guedes Bruni, pela leitura crítica do manuscrito. À CAPES, pela bolsa de mestrado concedida. Ao Programa de Pós-graduação do Instituto de Pesquisas Jardim Botânico do Rio de Janeiro, pela oportunidade de realização do trabalho. 


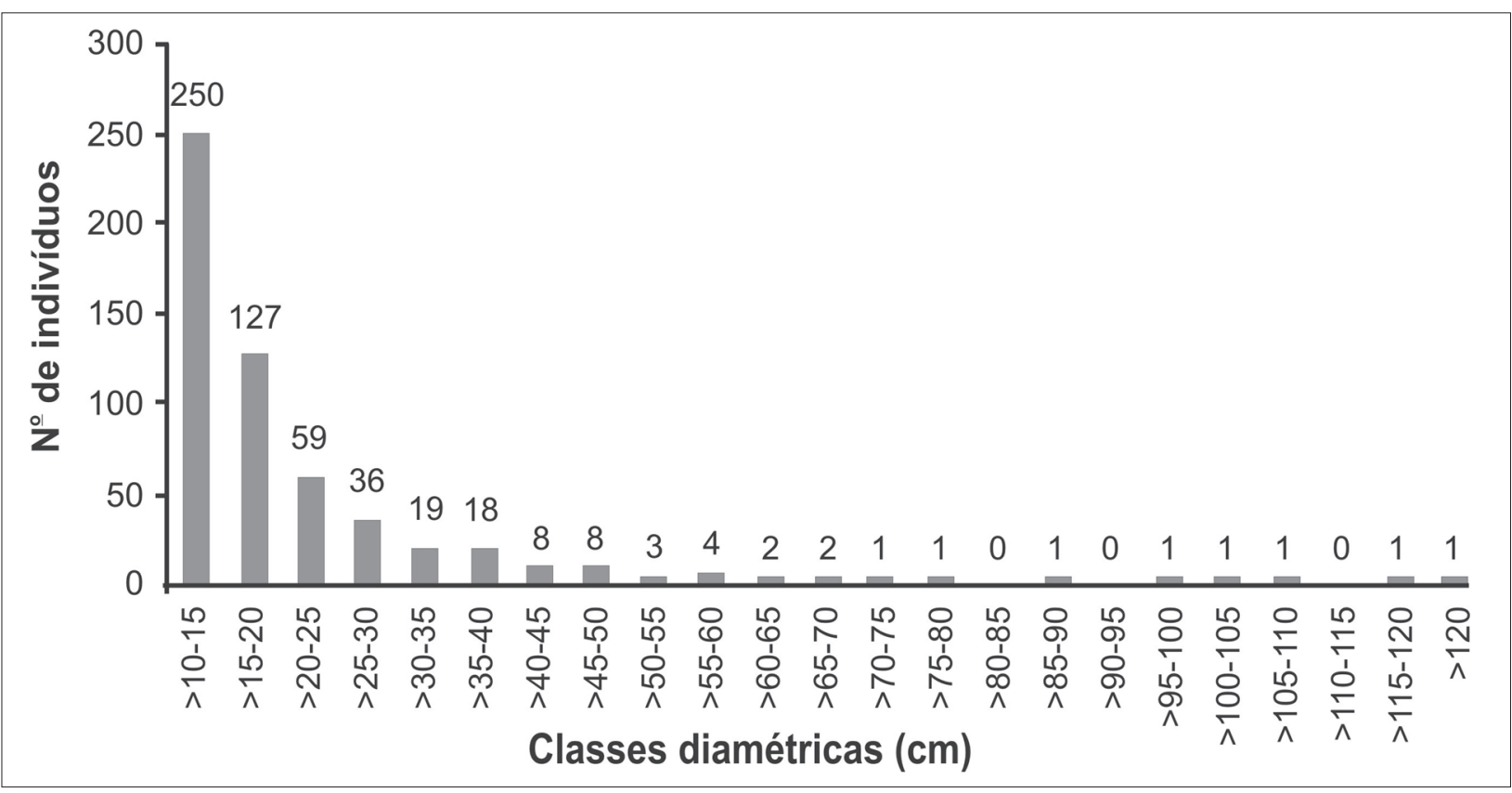

Figura 5. Distribuição da freqüência das classes de diâmetro de todas os indivíduos amostrados em um 1 ha de floresta de terra firme na vila de Caicubi, Caracaraí, Roraima, Brasil.

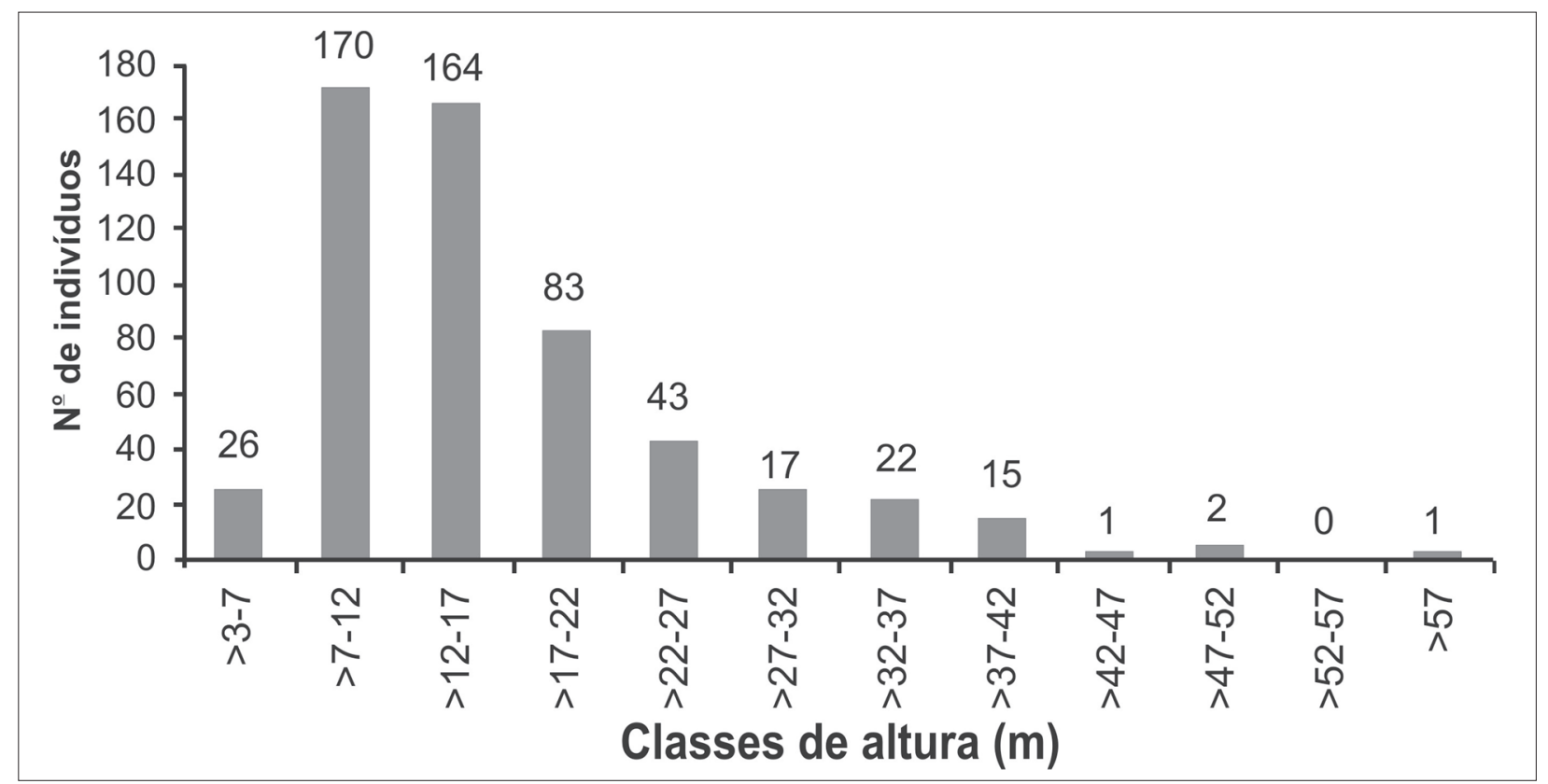

Figura 6. Distribuição da freqüência das classes de altura dos indivíduos amostrados em 1 ha de floresta de terra firme na vila de Caicubi, Caracaraí, Roraima, Brasil.

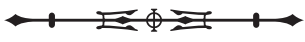




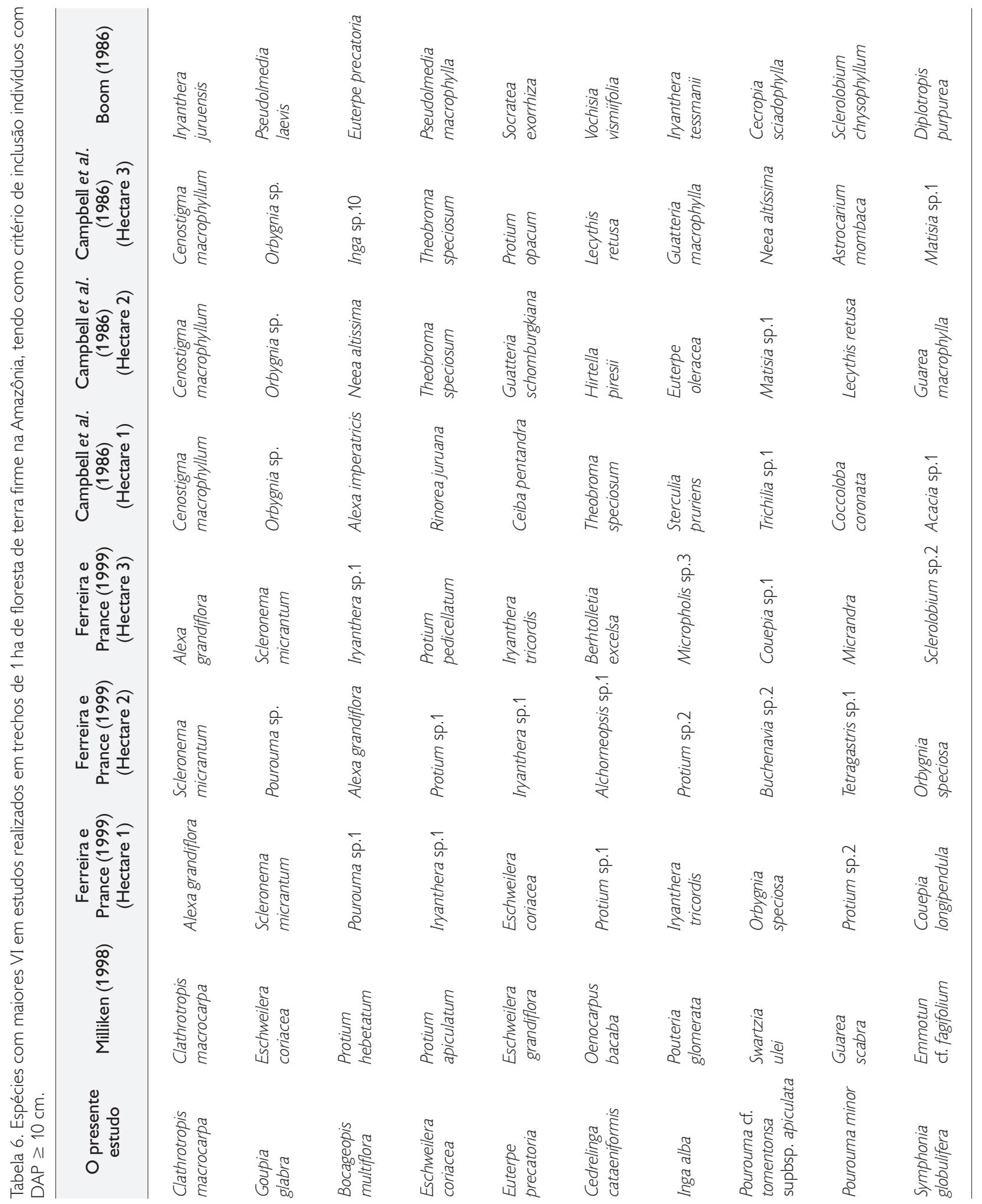




\section{REFERÊNCIAS}

BOOM, B. M. A. Forest inventory in Amazonian Bolivia. Biotropica, v. 18, n. 4, p. 287-294, 1986.

BRUMMITT, R. K.; POWEL, C. E. Authors of plants names. Kew, UK.: Royal Botanic Gardens, 1992. 732 p.

CAMPBELL, D. G.; DALY, D. C., PRANCE, G. T.; MACIEL U. N. Quantitative ecological inventory of terra firme and várzea tropical forest on the Rio Xingu, Brazilian Amazon. Brittonia, v. 38, n. 4. p. 369-393, 1986.

CAPOBIANCO, J. P. R. (Org.). Biodiversidade na Amazônia Brasileira. São Paulo: Instituto Socioambiental, 2001. 540 p.

CRONQUIST, A. An integrated system of classification of flowering plants: The New York Botanical Garden. New York: Columbia University Press, 1981. 1262 p.

FERREIRA, L. V.; G. T. PRANCE. Ecosystem recovery in terra firme forests after cutting and burning: a comparison on species richness, floristic composition and forest structure in the Jaú National Park, Amazonia. Botanical Jounal of the Linnean Society, v. 130, p. 97-110, 1999.

GENTRY, H. A. A Field guide to the families and genera of wood plants of Northwest South America (Colombia, Ecuador, Peru) with supplementary notes on herbaceous taxa. Washington: Conservation International, 1993. 895 p.

LAURANCE, W. F; FERREIRA, L. V.; RANKIN-DE-MERONA, J. M.; HUTCHINGS, R. W. Influence of Plot Shape on Estimates of Tree Diversity and Community Composition in Central Amazônia. Biotropica, v. 30, n. 4, p. 662-665, 1998.

MARTINS, F. R. Estrutura de uma floresta mesófila. Campinas: UNICAMP, 1991. $246 p$

MAGURRAN, A. E. Ecological diversity and its measurement. Princeton, New Jersey: Princeton University Press, 1988. 179 p.

MILLIKEN, W. Structure and composition of one hectare of central Amazonian terra firme forest. Biotropica, v. 30, n. 4, p. 530-537, 1998.

MORI, S. A. A família da castanha-do-pará: símbolo do Rio Negro. In: OLIVEIRA, A. A.; DALY, D. C. (Eds.). Florestas do Rio Negro. [S.l.]: Companhia das Letras/UNIP, 2001. p 119-141.

MUELLER-DOMBOIS, D.; ELLENBERG, H. Aims and methods of vegetation ecology. New York: John Wiley, 1974. 547 p.

NELSON, B. W.; OLIVEIRA, A. Área de Botânica. In: CAPOBIANCO, J. P. R. (Ed.) Biodiversidade na Amazônia Brasileira. São Paulo: Instituto Sócio-ambiental, 2001. p. 132-153.
OLIVEIRA, A.; NELSON, B. W. Floristic relationships of terra firme forests in the Brazilian Amazon. Forest Ecology and Management, v. 146, p. 169-179, 2001.

PIRES, J. M. Tipos de vegetação da Amazônia. Vegetalia-Escritos e Documentos, (IBILCE. UNESP) v. 4, p. 1-31, 1980

PIRES, J. M.; PRANCE, G. T. The Amazon Forest: A Natural Heritage to be Preserved. In: PRANCE, G. T.; ELLIAS, T. S. (Orgs.). Extintion is forever. New York: Botanical Garden, 1977. p. 158-194.

PIRES, J. M.; PRANCE, G. T. The vegetation types of the Brazilian Amazon. In: Prance, G.T.; Lovejoy, T.E. (Eds.). Key environments Amazônia. New York: Pergamon Press, 1985. p. 109-145

POLHIL, R. M.; RAVEN, P. H. Advances in Legume Systematics, Part 1. Kew: Royal Botanical Garden, 1981. 425 p.

RADAMBRASIL. (Projeto Radambrasil, Ministério das Minas e Energia). Levantamento dos Recursos Naturais, Volume 18. Folha AS. 20 Manaus; Geologia, geomorfologia, pedologia, vegetação e uso potencial da terra. Rio de Janeiro, 1978. 628 p., 7 mapas.

RIBEIRO, J. E. L. S.; HOPKINS, M. J. G; VICENTINI, A.; SOTHERS, C. A.; COSTA, M. A. S.; BRITO, J. M.; SOUZA, M. A. D.; MARTINS, L. H. P; LOHMANN,L.G.; ASSUNÇÃO, P. A. C. L.; PEREIRA, E. C.; SILVA, C. F.; MESQUITA, M. R.; PROCÓPIO, L. C. Flora da Reserva Ducke: guia de identificação das plantas vasculares de uma floresta de terra-firme na Amazônia Central. Manaus: INPA/DFID, 1999. $800 \mathrm{p}$.

SALOMÃO, R. P; SILVA, M. F. F.; ROSA, N. A. Inventário ecológico em floresta tropical de terra firme, Serra Norte, Carajás, Pará. Bol. Mus. Para. Emílio Goeldi, Belém, v. 4, n. 1, p. 1-46, 1988.

SHEPHERD, G. I. Fitopac 1: manual do usuário. Campinas: Universidade Estadual de Campinas, 1995. 93 p.

SWAINE, M. D. Population dynamics of tree species in tropical forests. In HOLM-NIELSEN, L. B., NIELSEN, I.C.; BALSLEV, H. Tropical forests, botanical dynamics, speciation and diversity. Scotland: University of Aberdeen, 1989. p. 101-110.

VElOSO, H. P., RANGel FILHO, A. L. R.; LiMA, J. C. A. Classificação da vegetação brasileira, adaptada a um sistema universal. Rio de Janeiro: Fundação IBGE, 1991. 123 p.

VILLA-NOVA, N. A.; SALATI, E.; MATSUI, E. Estimativa da evaporatranspiração na Bacia Amazônica. Acta Amazonica, Manaus, v. 6, n. 2, p. 215-228, 1976.

Recebido: 09/11/2005 Aprovado: 16/03/2007 